\title{
Role of epigenomics in ovarian and
}

\section{endometrial cancers}

Ovarian cancer is the most lethal gynecologic malignancy and while constituting only $3 \%$ of all female cancers, it causes 14,600 deaths in the USA annually. Endometrial cancer, the most diagnosed and secondmost fatal gynecologic cancer, afflicts over 40,000 US women annually, causing an estimated 7780 deaths in 2009. In both advanced ovarian and endometrial carcinomas, the majority of initially therapy-responsive tumors eventually evolve to a fully drug-resistant phenotype. In addition to genetic mutations, epigenetic anomalies are frequent in both gynecologic malignancies, including aberrant DNA methylation, atypical histone modifications and dysregulated expression of distinct microRNAs, resulting in altered geneexpression patterns favoring cell survival. In this article, we summarize the most recent hypotheses regarding the role of epigenetics in ovarian and endometrial cancers, including a possible role in tumor 'stemness' and also evaluate the possible therapeutic benefits of reversal of these oncogenic chromatin aberrations.

\section{KEYWORDS: decitabine DNA methylation endometrial cancer epigenetic biomarker HDAC inhibitor histone deacetylase histone methylation microRNA ovarian cancer}

\section{Ovarian cancer}

Epithelial ovarian cancer remains the most lethal gynecologic cancer in the USA, with over 14,600 deaths predicted in 2009 [301]. Its lifetime risk for all women is 1 in 71, with an overall lifetime mortality of 1 in 95 [1]. While the exact cause of ovarian malignanicies remains unknown, a hormonal risk is suggested by over $50 \%$ of deaths occurring in postmenopausal women aged 55-74 years. Genetic susceptibility factors are also contributory, including mutations in the breast cancer early onset genes $B R C A 1$ and $B R C A 2$. In addition, parity has been demonstrated to decrease ovarian cancer risk, with a negative correlation between the number of live births and disease incidence [2], and correspondingly, oral contraceptive use has also been found to be protective against disease development [3].

While localized ovarian cancer is highly curable (over $95 \%$-year survival), this stage represents only $18 \%$ of initial diagnoses (as early disease is generally asymptomatic), and survival falls to $29 \%$ for disseminated malignancies [4]. Consequently, early detection methods are critically needed. Based on its low overall incidence in postmenopausal women (1 in 2500), a logistically feasible detection method for ovarian cancer would require $75 \%$ sensitivity and $99.6 \%$ specificity; it is plausible that combinations of biomarkers could achieve those diagnostic criteria [5]. While unsuitable for widespread screening (due to insufficient sensitivity for early stage disease and its elevation by other conditions), the ovarian marker cancer antigen-125 (CA-125) is valuable for evaluating disease response and may be a diagnostically useful tool when assessed over a period of time $[5,6]$. Other biomolecules, including lysophosphatidic acid, human epididymis protein 4 (HE4; a protease implicated in sperm maturation) and the inhibins (members of the TGF- $\beta$ superfamily) are also elevated in the serum of ovarian cancer patients and may be of diagnostic value in various combinations with one another and/or with CA-125 [5,7]. Similar to CA-125, HE4 is also US FDA approved for monitoring disease progression [5]. Consequently, a recent diagnostic trial of CA-125 paired with HE4 demonstrated $76.4 \%$ sensitivity and $95 \%$ specificity, higher accuracy than for either marker alone [5]. Proteomic approaches may also hold promise and while early serum/plasma proteome biomarkers proved poorly reproducible for early detection, improved standardization of preanalytical processing and reference materials has renewed optimism for these methods [8,9]. In addition, as specific methylated DNA sequences have demonstrated promise as body fluid biomarkers for various other cancers $[10,11]$, and several such sequences associate with ovarian cancer, these could also ultimately be useful for ovarian cancer screening (likewise contingent

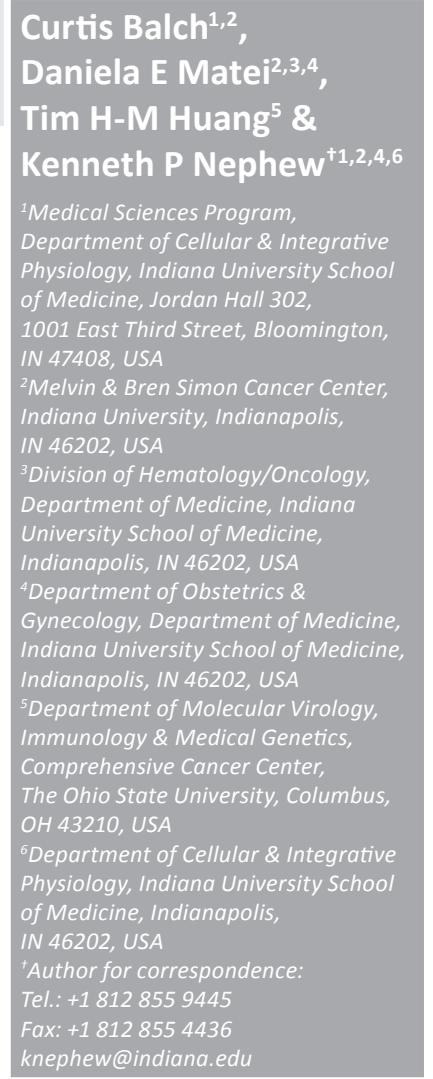

future medicine $_{\text {fsg }}$ 
upon standardized sample processing and reference markers) [12-14] (see 'DNA methylation \& histone deacetylation inhibitors' section).

The standard treatment for advanced ovarian cancers is surgical tumor debulking, followed by treatment with platinum/taxane combination; this results in complete responses in over $80 \%$ of patients [15]. Unfortunately, the majority of those responders relapse, after a median period of 20 months, owing to the onset of chemoresistance [15]. While second-line agents, such as gemcitabine and topotecan have shown some efficacy [15], agents targeting specific pathways (e.g., angiogenesis, PI3K/Akt and folate transport) may hold greater promise [16]. Finally, due to repressive epigenetic aberrations in ovarian tumors, it is possible that chromatin-modifying agents may also prove useful for the therapy of drug-resistant ovarian cancer, either singly or as chemosensitizers for conventional chemotherapeutics (see 'Conclusion and future perspective' section) $[12,13,17,18]$.

\section{Endometrial cancer}

Endometrial cancer (EC) is the most common gynecologic malignancy, with a lifetime risk of one in 38, and is the fourth most prevalent female neoplasm, with over 42,000 US cases annually. Despite an overall 5-year survival rate of $83 \%$, EC ranks second in mortality among female genital tract cancers, causing an estimated 7780 US deaths in 2009, with the death rate steadily increasing over the past 20 years $[19,301]$. In terms of economic impact, it is estimated that approximately US $\$ 1.8$ billion is spent annually in the USA on treatment of this disease [20], and a racial disparity also exists, with black women having a $61.3 \%$ overall 5 -year survival rate, as compared with $84.7 \%$ for white women [21]. While this disparity is partly due to socioeconomic factors and various comorbid conditions, distinct genetic [21,22] and epigenetic [23] differences also likely contribute to these divergent clinical outcomes (see 'Altered DNA metylation in endometrial tumors' section).

Endometrial cancers are subcategorized into type I and type II malignancies [24,25]. Type I tumors, the most common, develop in both preand postmenopausal women and are generally low grade, well-differentiated tumors of endometrioid histology [25]. These malignancies are often associated with hormonal imbalances, particularly estrogen exposure unopposed by progesterone [24]. By contrast, type II tumors are often poorly differentiated papillary, serous and clear cell carcinomas, occurring mainly in postmenopausal women. Type II cancers are also highly aggressive, more metastatic and are generally unassociated with hormonal risk factors [24].

The molecular mechanisms associated with type I estrogen-associated endometrial adenocarcinomas appear to be distinct from type II [24,26], with type I tumors frequently demonstrating microsatellite instability (associated with defective DNA mismatch repair), in addition to genetic (e.g., mutations, copy gains/losses) or epigenetic alterations (primarily promoter DNA methylation, see 'Altered expression of specific microRNAs in endometrial cancer' section) in KRAS, PTEN, MGMT, APC, hMLH1, PR-B and $\beta$-catenin $[24,27]$. By contrast, type II cancers exhibit less promoter hypermethylation and more frequent DNA mutations, with HER2/neu overexpression particularly associated with short survival [27]. Most ( 80\%) EC patients are detected with early stage I/II disease and are generally cured by surgery, often in combination with radiotherapy $[24,28]$. However, while the 5 -year survival rates for stage I and II ECs are 90 and 50\%, respectively, survival falls below 30\% for stage III and 5\% for stage IV malignancies [4], which are typically treated with various antimitotic or hormonal (for type I) therapies, although trastuzumab and other targeted therapies have demonstrated some degree of success [28-30].

Increased incidence of EC is also associated with the widespread use of unopposed estrogen among postmenopausal women. As progesterone antagonizes estrogen-induced proliferation of the uterine endometrium (inducing cytodifferentiation), two hormonal therapies for advanced or recurrent disease are the synthetic progestins megestrol and medroxyprogesterone. However, similar to chemo- and radio-therapeutic approaches, hormonal resistance frequently occurs in initially responsive stage III/IV disease [29,31], often by promoter DNA hypermethylation-induced silencing of the genes encoding estrogen receptor (ER) and the progesterone receptor (PR) [27]. As DNA methylation is potentially reversible (see 'DNA methylation \& histone deacetylase inhibitors' section), epigenetic therapies may prove useful for sensitizing poorly differentiated, receptor-negative or therapy-resisitant ECs to hormonal and other commonly used treatments (see 'epigenetic therapies for chemosensitization' section).

\section{Therapy resistance in ovarian $\&$ endometrial cancer}

While most $(\sim 80 \%)$ ovarian cancer patients respond completely to chemotherapy, the vast 
majority of those initial responders eventually develop relapse tumors that are in essence fully (and fatally) refractory to further interventions [15]. Similarly, while EC is frequently detected early, and thus highly curable, the advanced form of the disease behaves similarly to ovarian cancer (i.e., highly therapy responsive prior to drug-resistant relapse [29,31]). Most radio- and chemo-therapeutics, including those commonly used against endometrial and ovarian cancers, damage DNA or microtubules of rapidly proliferating cells, resulting in 'intrinsic' (i.e., mitochondrial- and p53-dependent) apoptotic pathways, while hormonal EC therapies are believed to elicit 'extrinsic' (i.e., p53-independent and death receptor-mediated) apoptotic cascades (Figure 1) [31,32]. Consequently, drug resistance can result from variations in a number of intra- or extra-cellular processes, including slow cell division or quiescence, metabolic drug inactivation, enhanced DNA repair, tubulin mutations and dysfunctional apoptotic response pathways [33]. In particular, hyperactivation of the IGF and MEK pathways are strongly associated with poor prognosis and platinum resistance in ovarian cancer [34], and moreover, numerous epigenetic aberrations can facilitate upregulation of IGF signaling (FIgure 1) $[35,36]$. Thus, while resistanceconferring phenotypes often result from genetic lesions (e.g., copy gains/losses), epigenetic aberrations may play an equivalent (or even greater) role in their development $[13,14,27]$ (see Figure 1 and 'Epigenetic aberrations in ovarian \& endometrial cancers $\&$ their possible use as disease biomarkers' section).

One emerging hypothesis for therapy resistance invokes the existence of multipotent malignant progenitors known as cancer stem cells (CSCs) believed to be fully responsible for tumor growth and progression [37]. It has been speculated that aggressive malignancies that initially undergo a complete response, followed by almost universal relapse (such as late-stage ovarian cancer and ECs), are likely to originate from tumor stem cells [37,38]. As normal tissue stem cells are typically long-lived, they must resist numerous environmental insults. Consequently, such cells often possess several of the abovementioned chemoresistance-conferring properties, including a low mitotic index, survival from hypoxia and enhanced DNA repair (in addition to the expression of ATP-dependent membrane transporters that expel toxic molecules), and it has been hypothesized that CSCs are likely to share many of these characteristics [38]. Candidate ovarian tumor stem cells have now been reported by several groups, including our own, as having the cell surface markers CD44 and CD117 [39], CD44 and MyD88 (a member of the NF-kB signaling pathway) [40] and CD133 [41,42]; moreover, those tumorigenic progenitors were more chemoresistant than unsorted tumor cells [39-41]. Similarly, in EC, a subfraction of 'side population' cells, capable of expelling a DNA-binding dye (based on the stem cell trait of multidrug transport) was resistant to paclitaxel and capable of mice tumor formation, while nonside population cells were not chemoresistant or tumorigenic [43]. Similarly, a subpopulation of dissociated, highly clonogenic human tumor cells were capable of mouse tumor formation using only 1000 cells [44], while another study demonstrated highly clonogenic CD133+ cells to be chemoresistant [45]. Thus, it is possible that targeting of endometrial and ovarian cancer progenitors could prevent (or possibly even reverse) tumor relapse. As it is now known that normal stem cells possess extensive epigenetic silencing of lineage/differentiation genes [46,47], and that epigenetics plays an essential role in normal differentiation [48], it is plausible that epigenetic therapies could disrupt the tumorforming and chemoresistance phenotypes of malignant progenitors (see 'Epigenetic therapies for the management of ovarian \& endometrial cancers' section).

\section{Epigenetic modulation of gene expression \\ DNA methylation \& \\ histone modifications}

The best known epigenetic phenomenon is transcriptionally repressive methylation of deoxycytosine (usually located within the dinucleotide $\mathrm{CpG}$ ), catalyzed by DNA methyltransferases (DNMTs) [49]. In normal cells, DNA methylation regulates the silenced allele of imprinted genes and also represses expression of potentially harmful DNA transposon sequences [50]. However, while most repetitive DNA sequences and heterochromatin are normally methylated, distinct CG-rich regions, usually within 5'-UTRs and the first exons of genes, are normally protected from this modification [51]. It is now established, however, that these ' $\mathrm{CpG}$ islands' are often hypermethylated in tumors, despite an overall global decrease in DNA methylation (i.e., global hypomethylation of repetitive sequences and non-CpG-island DNA) [49].

Another transcription-regulating epigenetic phenomenon is post-translational modification of histone proteins. Normally, in transcriptionally 


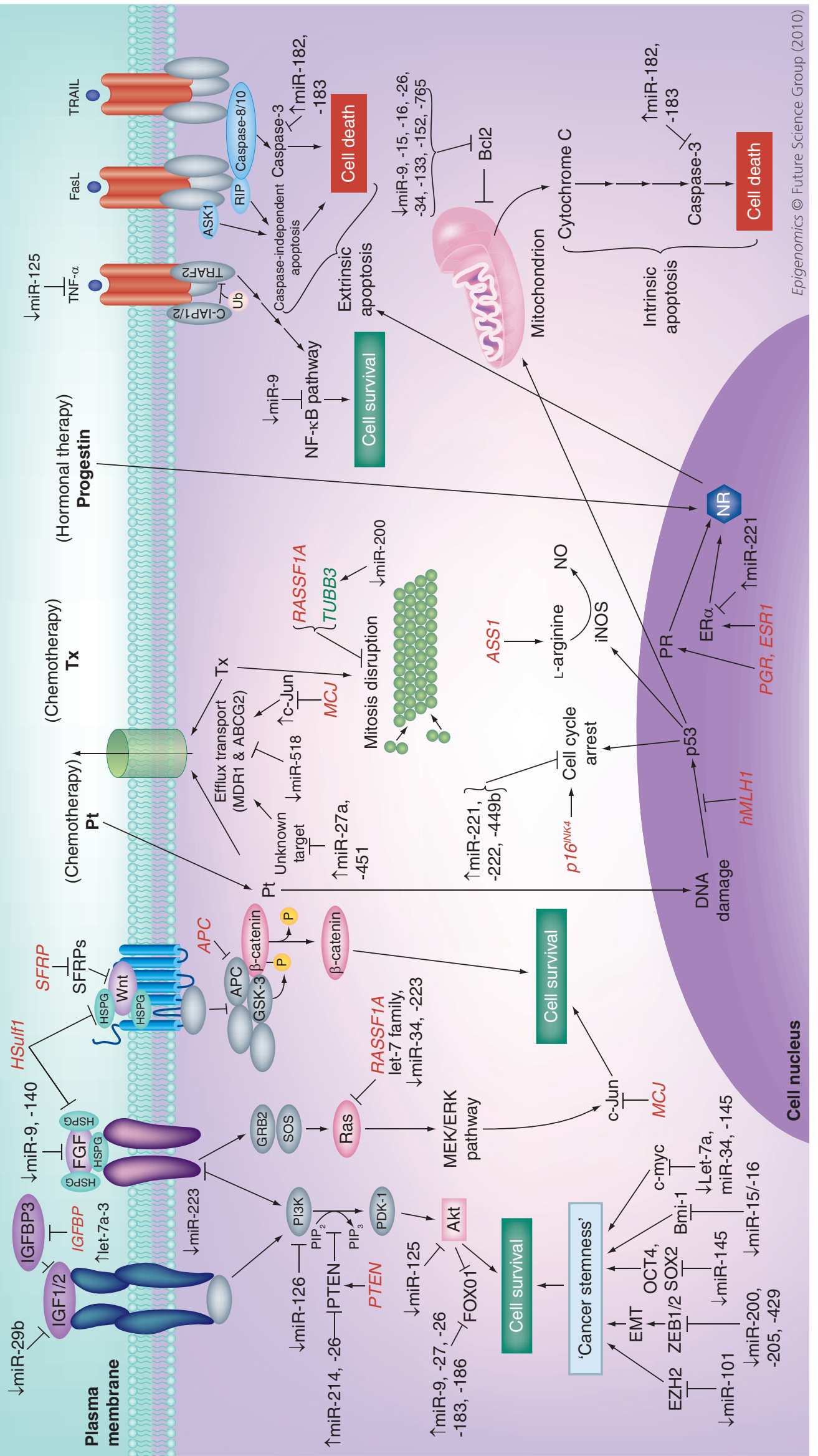

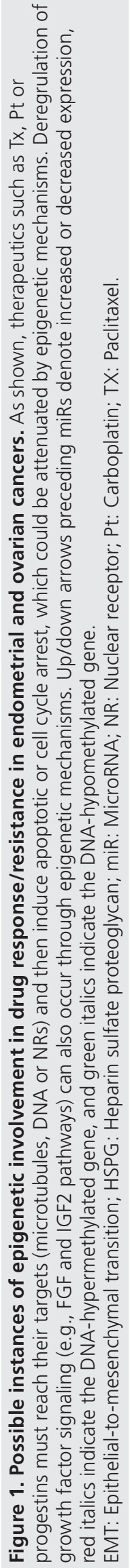


active genes, the $\varepsilon$-amines of lysines within the $\mathrm{N}$-terminal 'tails' of the core histones (H2A, $\mathrm{H} 2 \mathrm{~B}, \mathrm{H} 3$ and $\mathrm{H} 4$ ) are highly acetylated [49]. This modification neutralizes the positive charge of the basic histones and 'decompacts' nucleosomeassociated DNA, allowing access of transcription factors and polymerases to coding sequences. Consequently, hypoacetylated histones and histone deacetylases (HDACs) correlate strongly with gene silencing [49]. Similarly, various histone lysines are post-transcriptionally methylated, which is carried out by histone methyltransferases and reversed by histone demethylases [52]. The 'histone code' hypothesis posits that distinct histone 'marks' can be transcriptionally activating or repressive, depending on the specific residue [53]. For example, dimethylation of histone $\mathrm{H} 3$ lysine 9 and trimethylation of H3K27 (H3K27me3), are strongly associated with gene silencing. Conversely, trimethylation of histones $\mathrm{H} 3$ lysine 4 (H3K4me3) and H3K36 are well-established gene-activating marks [53]. In embryonic stem (ES) cells a number of differentiation-associated gene promoters simultaneously possess an activating histone mark, $\mathrm{H} 3 \mathrm{~K} 4 \mathrm{me} 3$, and a repressive histone mark, H3K27me3 [54]. Upon lineage commitment (e.g., to endodermal or mesodermal lineages), these discrepantly marked, 'bivalent' promoters lose either the activating or repressive mark (concordant with the gain of additional activating or repressive chromatin modifications), depending on the transcriptional status of the gene in the lineage-committed cell $[54,55]$. Interestingly, however, a large percentage of bivalently marked genes in ES cells are DNAmethylated in adult tumors [56].

As DNA methylation is strongly linked with gene repression, activating histone marks (e.g., H3K4me3) typically associate with DNA hypomethylation, while repressive marks (e.g., H3K9me2) often colocalize with DNA hypermethylation. For example, DNMTs can directly bind HDACs in large, heteromeric complexes, thus intimately linking these repressive epigenetic modifications [57], and HDACs form a complex with the H3K4me3 demethylase, thus further reinforcing gene repression [58]. In ES and tissue stem cells, similarly large chromatinmodifying complexes, known as Polycomb, repress differentiation-related genes, largely due to trimethylation of $\mathrm{H} 3 \mathrm{~K} 27$ [59].

\section{MicroRNA regulation of mRNA translation}

A recently discovered epigenetic phenomenon is post-transcriptional gene regulation by small
(19-24 base), noncoding microRNAs (miRs). miR primary transcripts may be several thousand bases long and undergo extensive processing prior to nuclear export of a semi-mature $70-80$ base precursor that is further refined to its mature form [60]. The mature, single-stranded $\mathrm{miR}$, which is then incorporated into a large ribonucleoprotein complex, binds to complementary mRNA 'target' sequences, resulting in mRNA degradation and/or translational blockade [61]. Over 850 mature human miRs have been discovered to date, with computational predictions of over 1000 [62], and any specific miR may target up to 200 distinct mRNAs (thus affecting $\sim 30 \%$ of the total transcriptome) [62]. MiRs have been widely linked to embryogenesis and development, and act to spatiotemporally 'fine tune' protein expression for processes such as cell-fate decisions or the maintenance of complex regulatory networks [61]. As might be expected, however, dysregulated miR expression may prompt numerous disease pathologies, including cancer [63]; consequently, miRs represent promising therapeutic targets and/or biomarkers. While miRs are believed to act predominantly as tumor suppressors [64], several are oncogenic [65] (see following section). Targeting specific miRs has now been performed using 'antagomiRs', both for mechanistic studies or investigation of possible in vivo therapeutic applications [66,67].

\section{Epigenetic aberrations in ovarian \& endometrial cancers \& their possible use as disease biomarkers}

\section{- Epigenetic alterations associated with ovarian carcinogenesis \\ Aberrant DNA methylation in ovarian tumors}

As mentioned above, cancer cells possess mislocalized DNA methylation and histone modifications, with global hypomethylation (largely of repetitive DNA) and localized hypermethylation, often within CG-rich CpG islands associated with the promoters of various tumor suppressor genes (TSGs), resulting in their transcriptional silencing. While genetic lesions (e.g., mutations, deletions and translocations) have long been associated with malignant transformation and progression, it is now evident that DNA methylation plays an equal or perhaps even greater role in carcinogenesis [68]. For example, although familial BRCA1 mutations are known to play a role in $5-10 \%$ of epithelial ovarian cancers, the second disruptive 'hit' to the non-mutated $B R C A 1$ allele is often via promoter methylation [14]. In a recent comprehensive review, it was found that TSGs 
such as $O P C M L$ (its function is largely unknown), TES (a regulator of cell motility) and RASSF1A (an inhibitor of the anaphase-promoting complex), are among the most frequently methylated genes in ovarian cancer [14]. Methylation of the TSG PTEN has also been observed in ovarian cancer [69], while two genes found to be highly discriminative between normal and malignant ovaries, HOXA10 and HOXA11, may play roles in very early ovarian tumor initiation [70,71]. Methylation-induced silencing of metastasis suppressors has also been associated with invasive ovarian cancer, including $C T G F$ (encoding the connective tissue growth factor) [72,73], CCBE1 (a hypothesized regulator of cell motility) [74], $\mathrm{HIC1}$ (a p53 target gene) [75], $C D H 13$ [76] and $C D H 1$, the loss of which is associated with upregulation of matrix metalloproteinases and the metastasis-promoting protein $\alpha$ 5-integrin [77]. Owing to the association of various methylated genes with ovarian cancer etiology, these sequences represent potential disease biomarkers (TABLE 1). Interestingly, specific ovarian cancer subtypes (e.g., serous adenocarcinomas and clear cell tumors), or disease with high versus low malignant potential, possess distinct methylation patterns $[14,36]$. While aberrantly methylated genes may accrue during aging (eventually leading to a growth advantage of the cells having those methylated genes), a subset of epithelial tumors possess a CpG island methylator phenotype (CIMP), defined as nonrandom, concordant methylation of two or more genes; CIMPs often associate with poor prognosis and chemoresistance [78,79]. The molecular mechanisms underlying CIMP remain largely unknown, with a role for overexpression of DNA methyltransferases considered fairly unlikely [78-81]. In ovarian cancer, one CIMP was represented by the concordant methylation of more than two genes out of HIC1, MINT25, MINT31 and $p 73$; that CIMP was inversely correlated with $B R C A 1$ methylation (thus defining the second CIMP) [82]. Similarly, in synchronous primary endometrial and ovarian carcinomas (the most common simultaneously occurring gynecologic malignancies), methylation of $h M L H 1, C D K N 2 A$ and $M G M T$ was found preferentially in the matched endometrial and ovarian tumors, suggesting methylation of these genes to be an early event in development of the two concordantly occurring malignancies [83]. Consequently, such tumor grade- and subtypespecific methylation patterns hold promise as biomarkers for a number of clinical correlates, including detection, staging, chemoresponse and outcome (TABLE 1$)$.
While single methylation markers may prove informative, many investigators are studying panels of such indicators (i.e., 'methylation signatures'), to increase the sensitivity and specificity of detection/prognostication (Table 1). One early methylation microarray-based assessment demonstrated the feasibility of genome-wide analyses of ovarian tumors for identifying such signatures [84], and in two subsequent similar studies by our group, we rigorously evaluated and validated several candidate markers, successfullly identifying 112 methylated loci that associate with shortened disease-free survival with $95 \%$ accuracy $[85,86]$. Another study demonstrated hypermethylation of at least one of six genes (BRCA1, RASSF1A, APC, p14ARF, p16INK4A and DAPK) in 41/50 ovarian cancer serum specimens ( $82 \%$ sensitivity), with no false positives (thus $100 \%$ specificity) and including 13 out of 17 stage I cases, supporting the possible use of these (and other DNA methylation markers) for early detection [87]. Although current response monitoring indicators, such as HE4 and CA-125, remain highly informative [7], epigenetic markers could supplement these approaches, possibly increasing sensitivity and specificity sufficiently for widespread population screening for early detection.

Although tumor methylation biomarkers will likely prove valuable for prognosis and various pathological determinations, the less invasive assessment of markers in body fluids (e.g., ascites, serum or plasma) is more feasible for monitoring of therapy response and possibly, for disease screening and detection. As shown in Table 1, a number of studies have now demonstrated impressive detection sensitivities and specificities using serum, plasma or peritoneal fluid, supporting the possible use of these (and other DNA methylation markers) for early detection and screening [87]. Moreover, a number of DNA methylation markers have been associated with chemosensitivity (TABLE 1), and thus will likely hold value as indicators of therapy response. In one study of ovarian cancer patient plasma, it was demonstrated that DNA methylation of $h M L H 1$ (encoding a mismatch repair enzyme) correlates significantly with drug-resistant tumor relapse following carboplatin/taxol therapy [88]. Thus, while hMLH1 methylation is rare in primary ovarian tumors [14], it may play a role in acquired platinum resistance [89,90]. Thus, in addition to providing greater insight into etiology, ovarian cancer-associated epigenetic events may also hold value for disease management. 


\section{Table 1. Possible epigenetic biomarkers for ovarian cancer prognostication.}

\begin{tabular}{|c|c|c|c|}
\hline Epigenetic marker $^{\dagger}$ & Tissue source & Clinical prediction & Ref. \\
\hline \multicolumn{4}{|l|}{ Detection } \\
\hline $\begin{array}{l}\text { Methylation of } \geq 1 \text { gene of } B R C A 1, \text { RASSF1A, } \\
A P C, p 14 A R F, p 16 I N K 4 A \text { or DAPK }\end{array}$ & $\begin{array}{l}\text { Serum, } \\
\text { peritoneal fluid }\end{array}$ & $\begin{array}{l}\text { Presence of malignancy ( } 82 \% \text { sensitivity for serum and } \\
93 \% \text { for peritoneal fluid), } 100 \% \text { specificity (all } \\
\text { tumor stages) }\end{array}$ & [87] \\
\hline 10-gene panel & Plasma & $\begin{array}{l}\text { Presence of malignancy ( } 85 \% \text { specificity and } \\
61 \% \text { sensitivity) }\end{array}$ & {$[230]$} \\
\hline $\begin{array}{l}\text { Methylation of } \geq 3 \text { genes of CYP39A1, } \\
\text { GTF2A1, FOXD4L4,EBP and HAAO }\end{array}$ & Tumor & Malignant vs non-malignant tissue & [231] \\
\hline \multicolumn{4}{|l|}{ Tumor stage, grade } \\
\hline MINT1, RASSF1A and CDH13 & Tumor & Her2/neu overexpression & [232] \\
\hline HOXA9 and SCGB3A1 & Tumor & Stage 1 or 2 tumors & [233] \\
\hline$E R \alpha, I G F B P-3, p 16, B R C A 1$ and $h M L H 1$ & Tumor & Highly malignant serous adenocarcinomas & [36] \\
\hline HOXA11 & Tumor & Suboptimal tumor debulking and poor outcome & {$[70]$} \\
\hline RASSF1A, GSTP1 and MGMT & Tumor & Invasive disease & [14] \\
\hline SPARC & Tumor & Tumor grade & {$[235]$} \\
\hline CDH13, CRABP1, HOXA9 and SCGB3A1 & Tumor & Tumor subtype & [233] \\
\hline CTGF & Tumor & Advanced stage & {$[72]$} \\
\hline CCBE1 & Tumor & Metastatic disease & [74] \\
\hline HICl & Tumor & Metastatic disease & {$[75]$} \\
\hline hMLH1, CDKN2A and MGMT & Matched tumors & Synchronous endometrial and ovarian cancer & [83] \\
\hline SFN, TMS1 and WTI & Tumor & Clear cell ovarian cancer & [14] \\
\hline ESR2 & Tumor & Platinum resistance & [92] \\
\hline hMLH1 & Plasma & Chemoresistant tumor relapse & [88] \\
\hline SFRP5 & Tumor & Platinum resistance & {$[93]$} \\
\hline $\begin{array}{l}\text { Methylation of }>1 \text { of BRCA1, GSTP1 and } \\
\text { MGMT }\end{array}$ & Tumor & Chemoresponse & [239] \\
\hline \multicolumn{4}{|l|}{ Disease-free/overall survival } \\
\hline FBXO32 & Tumor & Advanced stage and short DFS & {$[240]$} \\
\hline SFRP1, SFRP2 and SOX1 & Tumor & Short DFS & [241] \\
\hline SOX1, LMX1A and SFRP1 & Tumor & Short overall survival & {$[241]$} \\
\hline 112-gene panel & Tumor & Short DFS (95\% accuracy) & {$[85,86]$} \\
\hline Ribosomal DNA & Tumor & Long DFS & {$[242]$} \\
\hline $\begin{array}{l}\text { IGFBP3 combined with }>2 \text { genes of } C D K N 2 A \text {, } \\
\text { BRCA1 or } h M L H 1\end{array}$ & Tumor & Sevenfold increased risk of short DFS & {$[14]$} \\
\hline \multicolumn{4}{|l|}{ DNA-hypomethylated gene(s) } \\
\hline MAL & Tumor & Platinum resistance & [101] \\
\hline TUBB3 & Tumor & Taxane resistance & {$[105]$} \\
\hline 15-gene panel & Peritoneal fluid & Short overall survival & [243] \\
\hline
\end{tabular}




\section{Table 1. Possible epigenetic biomarkers for ovarian cancer prognostication (cont.).}

\section{Epigenetic marker $^{\dagger}$}

DNA-hypomethylated gene(s) (cont.)

SNCG, MASPIN and CLDN4

BORIS

Misexpressed miR(s) or altered miR processing

Decreased Dicer, Drosha mRNA

Downregulated let-7i

Downregulated 125a

Downregulation of miR-30c, $-130 \mathrm{a}$ and -335

Downregulation of miR-99b, -127 and -155

Decreased let-7i, miR-221, -30c, -152, -193

Increased miR-185, -106a, -181a, -210, -423,

$-103,-107$ and let-7c

Decreased miR-337, -368, -376a, -376b, -377, Tumor

$-410,-432$ and -495

Upregulation of miR-21, $-29 a,-92,-93$

and -126

Upregulated miR-199a-3p and-27a

Increased miR-27a and-451

Decreased miR-30c, -130a and -335

Increased let-7e

Decreased let-7e

Upregulated miR-378 and-625

Upregulation of miR-200a, $-200 \mathrm{~b}$ and -429

Increased miRs 100, 199a, 200a and 214

Upregulated miR-29b

Methylation of let-7a-3

Upregulated miR-23p, -125a-3p, -125a-5p,

$-130 a,-146 b-5 p,-193 a-3 p,-193 a-5 p,-423-5 p$,

-451 and $-491-5 p$

Upregulated $-34 a,-200 a,-200 b,-449 b$,

$-509-3 p,-509-3-5 p,-513 a-5 p$ and $-574-5 p$

Increased miR-302b, -22 and -373

Decreased miR-148b and -211

Increased miR-9, -96, -182, -183, -196a,

$-196 b,-205$ and -375

Increased miRs 7, 34c-5p, 146b-5p and 449a

Increased miR-30a, $-30 a^{*}$ and $-486-5 p$

Increased miR-302b, -325, -299-5p, -222 and

$-324-3 p$

Decreased miR-212 and -150

Increased miR-30a-5p, -29b and -30e-5p

Decreased miR-20a

Increased miR-325, -22, -302c, -299-5p, -373 Tumor

and $-196 b$

Decreased miR-9 and -18

Decreased miR-144 and -216

Decreased miR-101, -137, -211 and -215

Decreased miR-422b and 34c

Increased miR-23a, -27a, -21 and $-24-2$

Increased miR-449b

${ }^{+} D N A$-hypermethylated gene(s), possible clinical utility.

DFS: Disease-free survival; MiR: MicroRNA.

Tumor

Tumor

Tumor
Tissue source Clinical prediction

Ref.

Tumor Advanced stage and metastasis

[106-109]

Disease presence

[103]

Tumor

Suboptimal tumor debulking

$[115,116,120]$

Chemoresistance and short DFS

[244]

Tumor

Invasion and metastasis

[245]

Tumor

Paclitaxel and platinum resistance

[246]

Disease presence

Endometrial cancer vs normal endometrial and

Tumor

atypical hyperplasia

Poor survival

[117]

Serum

Disease presence

[174]

Tumor Platinum resistance

[130]

Tumor

Multidrug resistance

Drug-resistant

cancer cell lines

Cancer cell line

Drug-resistant

cancer cell lines

Tumor

Primary tumor

Tumor

Tumor

Tumor

Tumor

Resistance to six distinct chemotherapeutics

[247]

[246]

Paclitaxel resistance

[246]

Resistance to five distinct chemotherapeutics

[246]

(excluding paclitaxel)

Chemosensitivity

[130]

Long DFS and delayed recurrence

$[131,176]$

Late clinical stage and high-grade tumors

[125]

Short DFS and chemoresistance

[248]

Favorable prognosis

Stage III disease

Stage I disease

[130]

Serous vs nonserous disease

[126]

Tumor

Endometrioid disease

[249]

Tumor

Serous adenocarcinoma

[249]

Clear cell disease

[249]

Serous vs endometrioid disease

[126]

Tumor

Clear cell disease

[126]

Poor differentiation

[126]

Tumor Lymphovascular invasion [126]

Tumor Tubal involvement [126]

Tumor Decreased DFS [122]

Tumor Poor prognosis [130]

Tumor Good prognosis [130] 
As mentioned in the 'Therapy resistance in ovarian \& endometrial cancer' section, the majority of initially responsive, late-stage ovarian cancer patients relapse to a fully drug-resistant condition. Since most chemotherapies exert their effects by inducing apoptosis, it is now evident that chemoresistant tumor cells often possess defective or downregulated pro-apoptotic genes and/or overexpressed anti-apoptotic genes [33]. Consequently, in addition to mutations, DNA methylationinduced silencing of specific drug response genes also facilitates the development of ovarian tumor cell drug resistance [13], and it is likely that epigenetic aberrations affect several aspects of chemotherapeutic action in cancer cells, including membrane entry/exit, drug metabolism, cellular injury response (including DNA repair) and apoptosis (Figure 1). Hypermethylated genes implicated in platinum resistance include $h M L H 1$, the arginine biosynthesis-related gene ASS1, ESR2 (encoding the ER- $\beta$ ) and SFRP5, encoding an inhibitor of the oncogenic Wnt signaling pathway (Figure 1) [91-94]. Platinum resistance has also been correlated with stage-progressive hypermethylation of $M C J$, encoding a DNA-J protein believed to be a co-chaperone facilitating c-Jun degradation (preventing c-Jun transactivation of MDR1, encoding a multidrug efflux transporter) [95,96] and hypermethylation of $A N X A 11$ [97].

In addition to DNA hypermethylationinduced silencing of tumor suppressors, DNA hypomethylation also plays a significant role in ovarian cancer. In ovarian cancer this phenomenon occurs in heterochromatic Sat2 elements, and interestingly, is linked to hypermethylation of CDH1 and RNR1 [98], with recent studies even suggesting DNA demethylation to be an active process (rather than mere failure to maintain that epigenetic mark) [99]. Similarly, decreased methylation (i.e., greater hypomethylation) of LINE-1 elements has been correlated with high grade, advanced Federation of Gynecology and Obstetrics (FIGO) stage and poor prognosis in ovarian cancer patients [100]. In addition to repeated sequences, gene-specific hypomethylation occurs in ovarian cancer (typically a late event in disease progression) and has been associated with activation of oncogenes such as $M A L$ (linked to platinum resistance) [101], CLDN4 (an integral component of tight junctions) [102] and BORIS, an oncogene believed to contribute to tumorigenic epigenetic changes [103]. Hypomethylation and upregulation of the $A B C G 2$ multidrug transporter gene was also shown to occur during drug-acquired chemoresistance in two ovarian carcinoma cell lines (Figure 1) [104], and decreased methylation of metastasis promoters also occurs in late-stage ovarian cancers, including TUBB3 (a determinant of taxane resistance) [105], $S N C G$ [106], $M A S P I N$ [107] and the abovementioned CLDN4 (encoding an integral component of tight junctions) $[108,109]$. Thus, while aberrant DNA methylation is known to be a very early event in tumor initiation, it is likely that epigenetic alterations also contribute to end-stage disease.

Histone modifications also facilitate dysregulated gene expression in malignant disease. Suggestive of an overall global level of epigenetic repression, overexpression of the HDACs 1,2 and 3 (thus resulting in higher overall histone deacetylation) in ovarian and ECs correlates with high-grade tumors and poor prognosis [110]. Moreover, several genes now appear to be regulated solely by histone modifications (without alterations in DNA methylation), including the GATA family of differentiation-associated transcription factors and the cell cycle inhibitor p21 [111,112]. Similarly, Kwon et al. showed that $C L D N 3$, while DNA-hypomethylated (similarly to $C L D N 4$ ), is actually upregulated in ovarian cancer by loss of repressive histone modifications [113]. Moreover, using a platinum-resistant ovarian cancer cell line, we demonstrated that loss of transcriptionally repressive trimethylation at histone $\mathrm{H} 3$ lysine 27 (H3K27me3) caused reactivation of several tumor suppressors, with resensitization to cisplatin, suggestive of widespread gene silencing by that repressive histone mark in chemoresistant disease [114].

\section{Altered expression of microRNAs in ovarian cancer}

Dysregulated expression of miRs has also been demonstrated in ovarian tumorigenesis and disease progression. An overall ovarian tumor-suppressive role for miRs was suggested by greatly decreased mRNA levels of the miR-processing enzymes, Drosha and Dicer, in ovarian cancer tumors, as compared with controls $[115,116]$. Other studies, however, have reported insignificantly altered expression [117,118], or even gene amplification [119], of the miR processing machinery. Ovarian tumors possessing high Drosha and Dicer levels correlated with significantly increased survival, while low Dicer expression correlated with advanced tumor stage and low Drosha expression with suboptimal surgical cytoreduction $[115,120]$. These results would suggest that collectively, miRs act as tumor suppressors in this malignancy, and indeed, a number of mature miRs have been demonstrated to be 
downregulated in ovarian cancer, with one study showing advanced tumors had approximately $36 \%$ of miRs downregulated by copy number loss or epigenetic repression, as compared with the normal ovarian surface epithelium [117].

As might be expected, several miRs upregulated in ovarian cancer target pro-apoptotic, metastasis-suppressing or antiproliferation gene products, while downregulated miRs target growth signaling, prometastatic- or antiapoptosis-associated proteins (Figure 1). A partial list of ovarian cancer up- and downregulated miRs is shown in taвLE 2. Upregulated miRs include those found highly expressed in a number of other malignancies, including miR-10a/b, -21 , $-130 \mathrm{a},-221,-222$ and -223 while similarly, downregulated miRs included well-known tumor suppressors such as miR-9, -15a, $-16,-34,-125,-155$ and the let-7 family. However, one member of the let-7 family, let-7a-3, an oncogene in lung cancer [121], similarly appears to be oncogenic in ovarian cancer, as DNA hypermethylation of its promoter (and thus transcriptional silencing) associates with favorable prognosis [35]. With regard to famial ovarian cancer, another profiling study found no significant differences between the miR profiles of $B R C A 1 / 2$-asscociated or -unassociated ovarian cancers, suggesting no role for those tumor suppressors in ovarian tumor miR dysregulation [122].

Despite their fairly recent discovery, miR profiles have already proven to be highly predictive of specific malignancies, with distinct 'signatures' even capable of distinguishing particular cancer subtypes/stages and tumor histologies [123]. Consequently, similar to methylated DNA sequences, aberrantly expressed miRs likewise represent potential ovarian cancer biomarkers for detection, disease-free or overall survival and chemoresponse (TABLE 1), and can also be detected in body fluids and tumor-derived vesicles ('exosomes'), thus facilitating their (less invasive) use in screening or response monitoring. Based on their functions in embryonic and tissue stem cells, miRs may also play essential roles in CSCs (see Figure 1), with negatively correlated expression of two well known tumor-suppressing miRs, miR-15a and -16, with their target, Bmi1 , an oncoprotein essential for stem cell selfrenewal [124] while decreased miR-214 associated with upregulation of the pluripotency-associated miR-302d in primary ovarian tumors [125]. Likewise, miR-9, downregulated in ovarian cancer targets the NF- $\mathrm{kB}$ signal mediator, MyD88, a possible marker of ovarian cancer-initiating cells (see 'Epigenetic modulation of gene expression' section), while other downregulated miRs, miR-101, targets the stem-cell-associated oncoprotein EZH2 [126,127], while miR-34 and let-7 family miRs target c-Myc, a transcription factor that facilitates induced pluripotency [125,128,129] (Figure 1 \& Table 2). Similarly, the three clustered miRs, miR-200a, -200b and -429, downregulated in late-stage ovarian cancer $[130,131]$, were previously demonstrated to contribute to breast cancer cell stemness [132], suggesting that these may have a similar role (i.e., cancer stemness) in advanced ovarian cancer.

\section{Epigenetic alterations associated with endometrial cancer \\ Altered DNA methylation in endometrial tumors}

Differential methylation of multiple genes has also been reported in EC [133], indicating that epigenetic inactivation of gene promoters may likewise contribute to this disease. Indeed, aberrant DNA methylation appears to be more frequent than genetic alterations in ECs, with epigenetic abnormalities in genes encoding tumor suppressors, apoptosis inhibitors, cell cycle regulators, steroid receptors, transcription factors, angiogenesis modulators and oncoproteins (Figure 1) [133-135]. Specifically, a high frequency of methylation in tumors and cell lines has been reported for $A P C(\sim 40 \%), C A S P 8$ ( 35\%), CDH1 ( 25\%), ER $\alpha$-promoter-C (94\%), hMLH1 (41\%), PR-promoter-B (75\%), RASSF1A (33\%) and THBS2 (62\%) and a much lower frequency $(\sim 15 \%)$ of hypermethylation of p16INK4A (CDKN2A), p14ARF, p73 and PTEN [133,136-139]. Hypermethylation of the tumor suppressor RASSF1A, one of the most commonly methylated genes in solid tumors, is found in both early and late stage ECs [135], suggesting that epigenetic repression of this gene may contribute to both early and late carcinogenesis. Interestingly, promoter hypermethylation of the gene PER1 (period-1) was also found in EC tumors, suggesting a role for circadian rhythms in EC development [140]. Two reviews of four hormone-associated female cancers found that endometrial, breast, ovarian and colon cancers each display distinct DNA methylation patterns and thus are likely to rely upon different tumorigenic pathways $[133,135]$. Thus, similar to ovarian cancer (although fewer studies have been performed), DNA methylation profiles have strong potential as biomarkers for EC disease detection and prognosis (ТАBLE 3 ), as well as facilitating the identification of pathway-specific, targeted therapies (FIGURE 1). 


\section{Table 2. Partial list of dysregulated microRNAs and their possible oncogenic roles in ovarian cancer.}

\begin{tabular}{|c|c|c|c|c|c|}
\hline $\operatorname{miR}(s)$ & $\begin{array}{l}\text { Up-/ } \\
\text { down- } \\
\text { regulated }\end{array}$ & $\begin{array}{l}\text { Possible } \\
\text { mechanism(s) }\end{array}$ & Potential target(s) & $\begin{array}{l}\text { Possible consequence(s) } \\
\text { to tumor progression }\end{array}$ & Ref. \\
\hline $10 a$ and $b$ & $\begin{array}{l}\text { Up (late } \\
\text { stage) }\end{array}$ & $\begin{array}{l}\text { Hypoxia, mutation } \\
\text { and retinoic } \\
\text { acid target }\end{array}$ & $\begin{array}{l}\text { USF2, HOXA1, HOXD10, } \\
\text { HOXB1, HOXB3, RB1CC1 } \\
\text { and ribosomal proteins } \\
\text { (enhances translation) }\end{array}$ & $\begin{array}{l}\text { Drug resistance } \\
\text { Invasion/metastasis }\end{array}$ & {$[122,128,246,249,250]$} \\
\hline 21 & Up & $\begin{array}{l}\text { Hypomethylation } \\
\text { Stat3 target }\end{array}$ & $\begin{array}{l}\text { PDCD4 } 4^{+}, R^{R S 7^{+}}, N_{C A P G}^{+}, \\
\text {TPM1 and PTEN }\end{array}$ & $\begin{array}{l}\text { Reduced apoptotic potential } \\
\text { and anchorage independence }\end{array}$ & {$[118,122,126,130,174,246,251]$} \\
\hline $26 a$ and $b$ & Up & $\begin{array}{l}\text { Copy gain and } \\
\text { hypoxia }\end{array}$ & $\begin{array}{l}\text { PTEN, IL6, KPNA6, CTDSPL, } \\
\text { ITGA5 and EZH2 }\end{array}$ & Unknown & {$[117,122,249]$} \\
\hline $27 a$ and 451 & Up & Copy gain & $\begin{array}{l}\text { ZBTB10, Myt-1, HMGB2, } \\
\text { HOXA2 and CYP1B1 }\end{array}$ & $\begin{array}{l}\text { Multidrug export, oncogenic } \\
\text { signal transduction and } \\
\text { reduced apoptotic potential }\end{array}$ & {$[119,147]$} \\
\hline $99 b$ & Up & c-myc target & $\begin{array}{l}\text { SLC6A7, AIFM2, DNPEP, } \\
\text { HS3ST2, BIN1 and DOHH }\end{array}$ & $\begin{array}{l}\text { Chemotherapy resistance and } \\
\text { reduced apoptotic potential }\end{array}$ & {$[174,250,252]$} \\
\hline $130 a$ & $\begin{array}{l}\text { Up (late } \\
\text { stage) }\end{array}$ & c-myc activation & MCSF, GAX and HOXA5 & $\begin{array}{l}\text { Chemoresistance, } \\
\text { angiogenesis and } \\
\text { dedifferentiation }\end{array}$ & {$[130,253]$} \\
\hline $\begin{array}{l}141,199 a \\
200 a, b, c \text { and } \\
335\end{array}$ & $\begin{array}{l}\text { Up (primary } \\
\text { tumors and } \\
\text { exosomes) }\end{array}$ & Copy gain & $\begin{array}{l}\text { TGF } \beta, Z E B 1, Z E B 2, B A P 1, \\
\text { GATA4, GATA6, TNC, FN1, } \\
\text { EXOC5 and TUBB3 }\end{array}$ & $\begin{array}{l}\text { Mesenchymal-epithelial } \\
\text { transition }\end{array}$ & {$[119,253-255,176]$} \\
\hline $181 \mathrm{a}$ and b & Up & Unknown & $\begin{array}{l}\text { HOXA11, GATA6, NLK, } \\
C D X 2, T B L 1 X, D P P 6 \\
\text { and KLF2 }\end{array}$ & $\begin{array}{l}\text { Chemotherapy resistance, } \\
\text { dedifferentiation and cancer } \\
\text { stemness }\end{array}$ & {$[122,152,174,256]$} \\
\hline 182 & $\begin{array}{l}\text { Up (primary } \\
\text { tumors and } \\
\text { exosomes) }\end{array}$ & Copy gain & FoxO3 and FoxO1 & Invasion and metastasis & {$[122,247,253]$} \\
\hline 203 & Up & Hypomethylation & $\begin{array}{l}\text { p63, SOCS-3, ABL1, MCEF } \\
\text { and ADAMTS6 }\end{array}$ & Unknown & {$[122,126]$} \\
\hline 205 & Up & Hypomethylation & $\begin{array}{l}\text { ZEB1, ZEB2, E2F1, ERBB3, } \\
P K C \varepsilon \text { and SHIP2 }\end{array}$ & $\begin{array}{l}\text { Mesenchymal-epithelial } \\
\text { transition, oncogenic } \\
\text { signaling }\end{array}$ & {$[122,126,257]$} \\
\hline 213 & Up & Copy gain & $A P P$ and $S A T B 2$ & Chemotherapy resistance & {$[252]$} \\
\hline 214 & $\begin{array}{l}\text { Up (primary } \\
\text { tumors and } \\
\text { exosomes) }\end{array}$ & Copy gain & $\begin{array}{l}\text { SLC2AB, KSR1, JMJD2B, } \\
\text { EZH1, PLXNB3, NARG1 } \\
\text { and PTEN }\end{array}$ & $\begin{array}{l}\text { Cell proliferation and } \\
\text { oncogenic signal transduction }\end{array}$ & {$[119,125,253]$} \\
\hline $221 / 222$ & Up & Unknown & $\begin{array}{l}\text { KIT, AIP1, p21, p57, TCF12, } \\
\text { RIMS3 and ARNT }\end{array}$ & $\begin{array}{l}\text { Cell cycle progression } \\
\text { and angiogenesis }\end{array}$ & {$[118,122,158]$} \\
\hline 223 & Up & $\begin{array}{l}\text { PU.1, NF1-A and } \\
\text { C/EBP } \alpha\end{array}$ & $\begin{array}{l}\text { SEPT6 }{ }^{\dagger}, \mathrm{MMPO}^{\dagger}, \mathrm{USF}^{\dagger} \\
\text { KRAS and EGF }\end{array}$ & Unknown & {$[118,249,258]$} \\
\hline 296 & Up & $\begin{array}{l}\text { Various growth } \\
\text { factors }\end{array}$ & $\begin{array}{l}\text { LYPLA2, IQSEC2, RNF44 } \\
\text { and HGS }\end{array}$ & $\begin{array}{l}\text { Inhibition of apoptosis } \\
\text { and angiogenesis }\end{array}$ & {$[128,259]$} \\
\hline 340 & Up & Unknown & $\begin{array}{l}\text { PAM, RTN3, PPL, RNF34 } \\
\text { and ZNF513 }\end{array}$ & Chemotherapy resistance & [252] \\
\hline $518 b$ & Up & Unknown & MCF2L, WDR1 and TSN & Unknown & [128] \\
\hline $520 f$ & Up & $\begin{array}{l}\text { Oct3 target and } \\
\text { copy gain }\end{array}$ & $\begin{array}{l}\text { ZNF443, AK2, NFYA } \\
\text { and TCERG1 }\end{array}$ & $\begin{array}{l}\text { Cancer stemness, } \\
\text { chemotherapy resistance } \\
\text { and metastasis }\end{array}$ & {$[152]$} \\
\hline 605 & Up & Unknown & $\begin{array}{l}\text { VGLL3, PHACTR2, SCAMP1 } \\
\text { and SEC24D }\end{array}$ & $\begin{array}{l}\text { Enhanced oncogenic } \\
\text { signaling and } \\
\text { dedifferentiation }\end{array}$ & {$[128,260]$} \\
\hline 1 & Down & $\begin{array}{l}\mathrm{C} / \mathrm{EBP} \alpha \\
\text { downregulation }\end{array}$ & $\begin{array}{l}\text { FOXP1, HDAC4 c-Met, Pim1 } \\
\text { and HAND2 }\end{array}$ & $\begin{array}{l}\text { Tumor growth, cell motility } \\
\text { and cell proliferation }\end{array}$ & {$[126,261]$} \\
\hline 9 & Down & $\begin{array}{l}\text { DNA methylation } \\
\text { and copy loss }\end{array}$ & $\begin{array}{l}N F-\kappa B^{\dagger}, B c / 2^{\dagger}, B c / 6, F G F^{\dagger} \\
\text { and } b-R a f\end{array}$ & $\begin{array}{l}\text { Oncogenic signal } \\
\text { transduction }\end{array}$ & {$[118,119,126,262]$} \\
\hline
\end{tabular}




\begin{tabular}{|c|c|c|c|c|c|}
\hline $\operatorname{miR}(s)$ & $\begin{array}{l}\text { Up-/ } \\
\text { down- } \\
\text { regulated }\end{array}$ & $\begin{array}{l}\text { Possible } \\
\text { mechanism(s) }\end{array}$ & Potential target(s) & $\begin{array}{l}\text { Possible consequence(s) } \\
\text { to tumor progression }\end{array}$ & Ref. \\
\hline $15 a$ and16a & Down & $\begin{array}{l}\text { Copy loss and } \\
\text { DNA methylation }\end{array}$ & $\begin{array}{l}\text { BAZ2A, BCl2, CCND1, } \\
\text { WNT3, BMI-1 } 1^{+}, E T S 1, C-J U N \\
\text { and MCL1 }\end{array}$ & $\begin{array}{l}\text { Cancer cell stemness, } \\
\text { apoptosis inhibition } \\
\text { and proliferation }\end{array}$ & {$[117,119,124,129]$} \\
\hline $29 c$ & Down & c-Myc repression & $\begin{array}{l}\text { COL4A2, FUSIP1, TDG } \\
\text { COL3A1, IFI30 and KLHDC2 }\end{array}$ & $\begin{array}{l}\text { Invasion/metastasis and } \\
\text { chemotherapy resistance }\end{array}$ & {$[177,247,263]$} \\
\hline $30 b$ and $d$ & Down & Unknown & CTGF & Invasion/metastasis & {$[118]$} \\
\hline $34 a, b$ and $c$ & Down & $\begin{array}{l}\text { Copy loss, DNA } \\
\text { methylation and } \\
\text { p53 target }\end{array}$ & $\begin{array}{l}\text { SIRT1, MYC, NOTCH, BCL2, } \\
\text { CCND1 and WNT3 }\end{array}$ & $\begin{array}{l}\text { Cancer stemness and } \\
\text { apoptosis inhibition }\end{array}$ & {$[117,122,126,128,129]$} \\
\hline 95 & Down & $\begin{array}{l}\text { DNA methylation } \\
\text { and copy loss }\end{array}$ & $A / B 1$ and $G N A / 2$ & $\begin{array}{l}\text { Cell proliferation and } \\
\text { anchorage-independence }\end{array}$ & {$[117,119,264]$} \\
\hline 98 & Down & Unknown & HMGA2, LIN28B and HIC2 & $\begin{array}{l}\text { Oncogenic signaling and } \\
\text { cancer stemness }\end{array}$ & [128] \\
\hline $125 a$ and $b$ & Down & $\begin{array}{l}\text { PEA3 target } \\
\text { (ETS family) and } \\
\text { mutation }\end{array}$ & $\begin{array}{l}\text { LIN28b, Akt3, ETS1ARID3B, } \\
\text { ERBB2, TNF } \alpha \text { and BMPR1B }\end{array}$ & $\begin{array}{l}\text { Epithelial-mesenchymal } \\
\text { transition, metastasis and } \\
\text { oncogenic signal transduction }\end{array}$ & $\begin{array}{r}{[118,122,125,126,245,246,} \\
250,257]\end{array}$ \\
\hline 126 & Down & DNA methylation & $\begin{array}{l}\text { SPRED1, PIK } 3 R 2, \text { RGS4, } \\
\text { RGS5 and PI3K }\end{array}$ & Angiogenesis & {$[122,174]$} \\
\hline 137 & Down & Copy loss & $\begin{array}{l}\text { CDK6, MITF, KLF12 } \\
\text { and PDLIM3 }\end{array}$ & $\begin{array}{l}\text { Cell cycle progression and } \\
\text { dedifferentiation }\end{array}$ & {$[117,126]$} \\
\hline 140 & Down & Copy loss & c-SRK, MMP13 and FGF2 & $\begin{array}{l}\text { Oncogenic signal } \\
\text { transduction }\end{array}$ & {$[117,126]$} \\
\hline 145 & Down & $\begin{array}{l}\text { Copy loss and loss } \\
\text { of p53 }\end{array}$ & $\begin{array}{l}\text { MAP3K3, MAP4K4, SOX2, } \\
\text { OCT4, KLF4 and c-myc }\end{array}$ & $\begin{array}{l}\text { Oncogenic signal } \\
\text { transduction }\end{array}$ & {$[117,126,265]$} \\
\hline 150 & Down & Copy loss & $\begin{array}{l}\text { c-Myb, MAK9, Akt3 } \\
\text { and MAP2K4 }\end{array}$ & $\begin{array}{l}\text { Oncogenic signal } \\
\text { transduction }\end{array}$ & {$[117]$} \\
\hline 184 & Down & $\begin{array}{l}\text { Copy loss and } \\
\text { DNA methylation }\end{array}$ & TTK69, K10 and Sax(A) & Dedifferentiation & {$[117]$} \\
\hline $\begin{array}{l}\text { 199a, 200a, b, } \\
\text { c and } 429\end{array}$ & $\begin{array}{l}\text { Down (late } \\
\text { stages) }\end{array}$ & Copy loss & $\begin{array}{l}\text { ZEB1, ZEB2, FN1, PPM1E, } \\
\text { EXOC5, GATA4, GATA6, } \\
\text { TUBB3, TNC and TGF- } \beta\end{array}$ & $\begin{array}{l}\text { Epithelial-mesenchymal } \\
\text { transition, metastasis and } \\
\text { chemoresistance }\end{array}$ & {$[130-132,255]$} \\
\hline 210 & Down & Copy loss & $\begin{array}{l}\text { E2F3', EFNA3, HoxA1 and } \\
\text { HoxA9 }\end{array}$ & $\begin{array}{l}\text { Cell cycle dysregulation, } \\
\text { oncogenic signaling and } \\
\text { dedifferentiation }\end{array}$ & {$[109,119,266,267]$} \\
\hline 335 & Down & Unknown & $\begin{array}{l}\text { P18SRP, HLF, CALU, MAX, } \\
\text { HOXD8, SOX4, JAG1, TNC, } \\
\text { c-Met and TNC }\end{array}$ & $\begin{array}{l}\text { Oncogenic signal } \\
\text { transduction, } \\
\text { invasion/metastasis } \\
\text { and chemoresistance }\end{array}$ & {$[128,246,268]$} \\
\hline 377 & Down & DNA methylation & REST and SOD1 & $\begin{array}{l}\text { Cancer stemness and } \\
\text { oxidative damage }\end{array}$ & {$[117,249]$} \\
\hline $517 a$ and $b$ & Down & Unknown & $\begin{array}{l}\text { CREAP-1, MAPKAPK5, } \\
\text { NFKBIE and PTK } 2 B\end{array}$ & $\begin{array}{l}\text { Chemotherapy resistance and } \\
\text { oncogenic signal transduction }\end{array}$ & {$[122]$} \\
\hline 519a, d and e & Down & DNA methylation & $\begin{array}{l}\text { FLJ31818, TGFBR2, HUR, } \\
\text { EIF2C1, ARID4B, GATA2BD } \\
\text { and SUV39H1 }\end{array}$ & $\begin{array}{l}\text { Cell proliferation and } \\
\text { epigenetic gene silencing }\end{array}$ & {$[122,128,269]$} \\
\hline $551 a$ & Down & Copy loss & LPHN1, ERBB4 and ZFP36 & $\begin{array}{l}\text { Oncogenic signal } \\
\text { transduction }\end{array}$ & {$[128]$} \\
\hline 662 & Down & Unknown & NEGR1, MKX and CSF3 & Unknown & {$[128]$} \\
\hline $\begin{array}{l}\text { Let- } 7 b, d \text {, e } \\
\text { and } f\end{array}$ & Down & Copy loss & $\begin{array}{l}\text { c-Myc, KRAS, HMGA2, IL-6, } \\
\text { LIN28B and HIC2 }\end{array}$ & $\begin{array}{l}\text { Oncogene activation, } \\
\text { drug resistance and } \\
\text { cancer stemness }\end{array}$ & {$[117,125,128,129,246]$} \\
\hline Let-7i & Down & Unknown & $\begin{array}{l}\text { HMGA2, LIN28Bm TRIM71 } \\
\text { and IGF2BP1 }\end{array}$ & Chemotherapy resistance & [244] \\
\hline
\end{tabular}


Aberrant DNA methylation also associates with microsatellite instability (MSI) in 17-25\% of ECs, a phenotype correlated with defective DNA mismatch repair [141]. DNA mutations in MSI-related mismatch repair genes (including hMLH1, MGMT, WRN and BRCA1) are rare, with their transcriptional silencing predominantly due to epigenetic repression [142]. However, a separate, extensive study demonstrated MGMT methylation to be rare, further suggesting the expression and activity of the MGMT enzyme, which is likely to contribute to limited EC responses to alkylating agents [143]. MSI is further associated with a 'mutator phenotype,' characterized by widespread gene mutation and genomic instability [144]. Although it remains controversial whether MSI associates with clinical outcome in EC [145], distinct patterns of epigenetic changes in MSI-positive and MSI-negative EC have been demonstrated. For example, MSI-positive disease is strongly associated with promoter hypermethylation of hMLH1, PTEN, APC, SFRP1, SFRP4 and RASSF1A [146-149] and one methylation microarray study by our group demonstrated $h M L H 1$ methylation to associate with methylation of SESN3 (involved in antioxidant defense) and TITF1 (thyroid transcription factor-1) [150]. Interestingly, single molecule sequencing revealed significant heterogeneity of $h M L H$ methylation in endometrial tumors, suggesting a role specific to a distinct tumor subpopulation [151].

\section{Table 3. Candidate epigenetic biomarkers for endometrial cancer prognostication.}

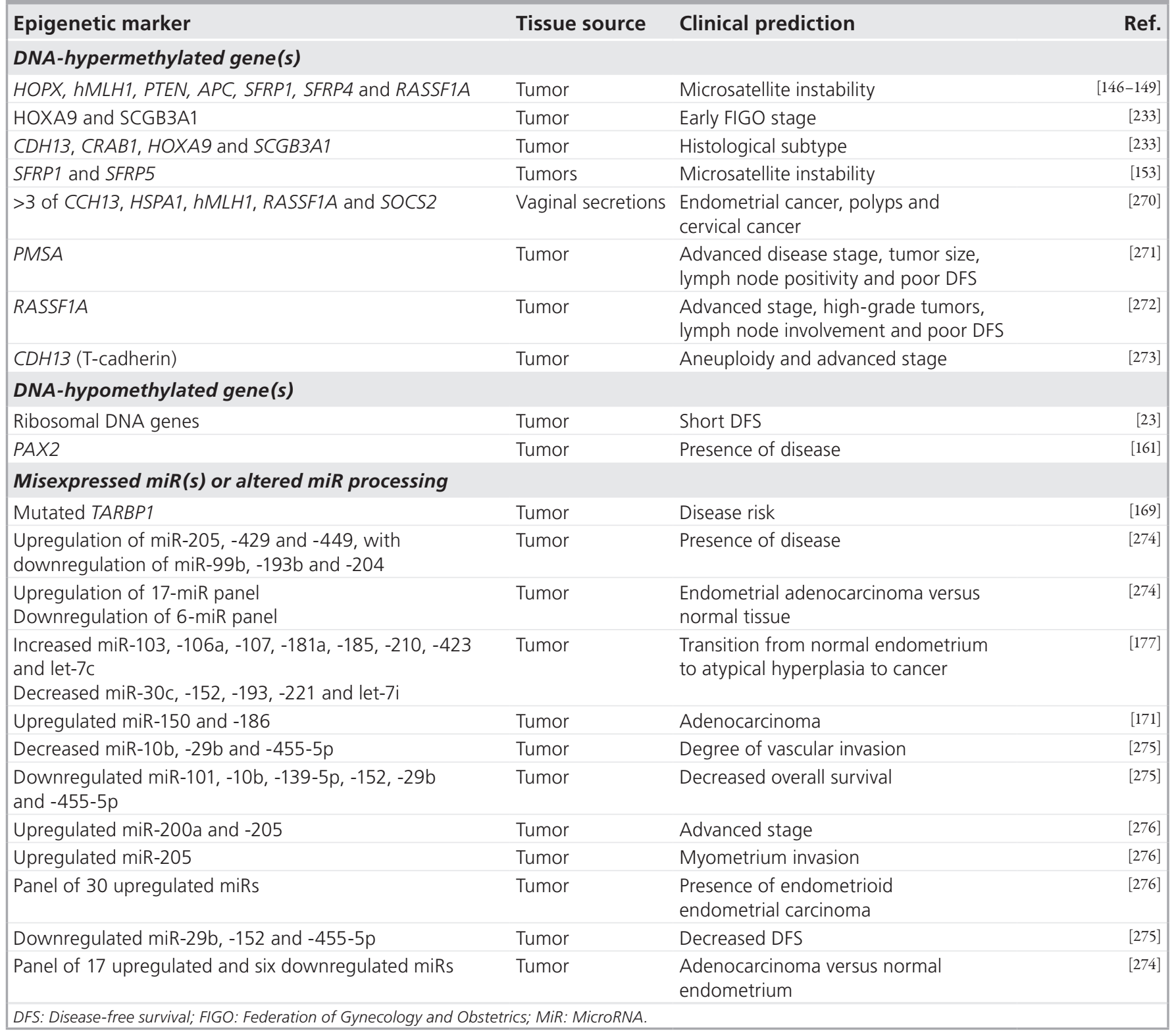


DNA methylation-induced silencing of specific genes may also correlate with genetic mutations in MSI-positive EC. For example, concomitant RASSF1A methylation and KRAS/BRAF mutations were found only in MSI-positive disease, as RASSF1A methylation and KRAS/BRAF mutations were shown to be mutually exclusive in MSI-negative ECs [135]. Frequent downregulation of two members of the secreted frizzledrelated protein family (SFRP1 and SFRP4) was also seen in MSI-positive ECs, with decreased SFRP1 correlated with hypermethylation of its gene promoter [152]. Specifically, SFRPs negatively regulate Wnt signaling (Figure 1), an embryogenesis-associated cascade that may also facilitate self-renewal in CSCs [153]; consequently, SFRP family genes have been denoted as 'epigenetic gatekeepers' [154]. MSI in endometrial tumors has been associated with a CIMP (see 'Aberrant DNA methylation in ovarian tumors' section), demonstrated by the coordinated methylation of HOXA11 and THBS2 [138]. Taken together, these findings suggest that there are unique epigenetic signatures for MSI-associated cancers and similar to other cancers, a number of these methylated genes represent candidate biomarkers for EC prognostication and clinical decision-making (TABLE 3).

Epigenetics also influences the steroid receptor cascades in EC. Estrogen receptor signaling plays a key role in the development and progression of type 1 endometroid adenocarcinomas [155], including the late-stage phenotypes of drug resistance and tumor vascularization $[26,147]$. By contrast, the female sex steroid hormone progesterone, through the action of its specific receptors (PRs), protects the endometrium against the hyperplastic effects of estrogens $[156,157]$. Consequently, the specific protein levels of ER and PR in uterine cells are critical for appropriate cellular responses to estrogens and progesterone, respectively, and disruption of either of these receptors is associated with more aggressive endometrial malignancies, leading to abnormal estrogen signaling, lack of normal progesterone protection against estrogenmediated growth promotion and malignant progression [158]. Silencing of both $E R$ and $P R$ by aberrant DNA methylation frequently occurs in EC $[133,134,159,160]$, and can be reversed by the demethylating agent 5-aza-2'-deoxycytidine (see 'Epigenetic therapies for the management of ovarian \& endometrial cancers' section) [134,159]. Furthermore, female sex steroid hormones may also induce distinct DNA methylation-based signatures in EC [78,133].
A role for DNA hypomethylation also contributes to EC progression, with the transcription factor-encoding $P A X 2$ shown to be methylated and silenced in normal adult, but not malignant, endometrial cells [161]. More aggressive type II EC tumors possess significantly reduced levels of DNA methylation (i.e., greater hypomethylation), as compared with the less aggressive type I ECs, possibly contributing to the type II EC characteristic of genomic instability [27]. In addition, decreased DNA methylation of ribosomal DNA genes associates with shortened overall survival and many African-American women, who suffer disproportionately worse outcomes from EC (even after controlling for socioeconomic factors and tumor stage/grade), possess notably lower ribosomal DNA methylation than nonAfrican-American women [23]. Consequently, DNA methylation changes contribute in numerous ways to EC and profiles of such alterations will likely be valuable for prognosis and therapeutic decision-making.

A role for epigenetics in endometrial pathologies is further supported by hormoneinduced imprinting of DNA methylation patterns. McLachlan and coworkers, as well as others, demonstrated that in utero or neonatal exposure to diethylstibesterol 'hormonally imprinted', via DNA methylation changes, specific mice genes that become constitutively expressed in adult uteri and in tumor, including demethylation of estrogen-responsive genes [162-164]. Perinatal diethylstibesterol exposure also associates with hypermethylation of the developmental regulators HOXA10 and HOXA11, linked to reproductive tract abnormalities [165], and intriguingly, to a transgenerational susceptibility to uterine tumors and aberrantly methylated ER target genes (resulting in abnormal hormone response), passed through the maternal lineage to subsequent descendents [162,163]. Thus, uterine exposure to endocrine disruptors, during early neonatal development, may promote an epigenetic transgenerational phenotype, presumably due to permanent reprogramming of imprinted DNA methylation patterns. Furthermore, based on evidence for the existence of endometrial progenitor cells [166,167], one could postulate that epigenetic insults to endometrial stem cells could result in altered endometrial gland methylation patterns and aberrant endometrial stem cell proliferation [168], ultimately, increasing susceptibility to malignant disease. 


\section{Altered expression of specific miRs in endometrial cancer}

Dysregulated expression of miRs is also common in EC (TABLE 4), with a collective miR tumor suppressor function suggested by frequent mutation in a Dicer-1 complex-associated protein, TARBP1 (thus affecting miR processing in general) [169]. As expected, EC-upregulated miRs typically include those targeting proapoptotic or antiproliferation gene products (miR-96, -150, -185, -186 and -513a-5p), while downregulated miRs consist of those targeting metastasis promoters (miR-1, -193, -455-5p and -765) and anti-apoptotic transcripts (miR-26, $-133,-196,-377$ and $-542-3 p / 5 p$ ) (Table 4). In EC cell lines, it was also demonstrated that the tumor suppressor FOXO1 is cooperatively downregulated by miR-9, -27, -96, -153, -182, -183 and -186 [170], while EC tumors overexpress miR-186 and -150 , concordant with underexpression of their target protein, the pro-apoptotic, ATP-binding receptor P2X7 [171] and miR-196, which targets ANXA11 [172], similar to ovarian cancer, in which ANXA11 is silenced by DNA methylation [97]. While several EC-associated miRs are repressed by DNA methylation (TABLE 4), miR-129-2 is silenced by histone deacetylation, allowing upregulation of its target, the oncogenic transcription factor SOX4 [173].

Similar to ovarian cancer, specific EC-dysregulated miRs associate with a number of clinical correlates, including tumor stage/grade, lymph node involvement and subtype, and thus also represent promising disease biomarkers (TABLE 3). For example, a microarray microchip [174] assessment identified a miR profile capable of distinguishing normal from endometrial tumor specimens (90\% accuracy), and early from advanced stage disease $(94.5 \%$ accuracy) [175]. Consequently, these approaches hold future potential for possible individualized treatment based on EC epigenetic indicators.

A number of miRs have also been implicated in EC drug resistance and possible cancer stemness, including the upregulated miR-155, $-182,-185$ and the downregulated miR-30c, $-101,-455-5 p$ and $-518 c$ (Table 3). Another well known tumor suppressive $\mathrm{miR}, 200 \mathrm{c}$, mediates chemosensitivity of aggressive EC cell lines by targeting mesenchyme-associated factors (e.g., ZEB1 and ZEB2) and class III $\beta$-tubulin (encoded by $T U B B 3$ ), which is also hypomethylated and upregulated in taxane-resistant ovarian cancer cells (Figure 1) [105,176]. By combining $\mathrm{miR}$ expression profiles with those of their target mRNAs or proteins, it is possible to determine an overall perspective of the 'network' of active/inactive miR-affected pathways responsible for the drug-resistant phenotype. One such comparison of the target mRNAs of 13 EC-dysregulated miRs to gene-expression profiles allowed the prediction of a number of altered biological pathways, including cell death, proliferation and carcinogenesis [177]. Our group has similarly developed an open access algorithm [302] for identifying mRNA targets with expression inversely correlated to their putative targeting miRs (based on gene and $\mathrm{miR}$ expression profiles), likewise providing comprehensive pathway analyses [178]. Thus, using systems biology approaches to integrate EC miR expression patterns with other 'omics data can yield valuable insight into possible mechanisms of drug resistance, facilitating the development of more effective therapies.

Ovarian steroids also regulate miR expression profiles, both in normal endometrial function (i.e., estrous cycling and pregnancy) and in various pathologies. For example, of seven PCR-validated miRs differentially expressed between isolated stromal cells and glandular epithelial cells, three were dysregulated by treatment with $17-\beta$-estradiol and medroxyprogesterone; those effects were partially reversible by treatment with the ovarian steroid antagonists, fulvestrant and RU-486 [179]. Similarly, another study identified $12 \mathrm{miRs}$ upregulated during mid-secretory phase, in concordance with estrogen- and progesterone-induced cell cycle changes occurring in luminal and glandular epithelial cells [180]. Consequently, similar to other steroid hormone-associated malignancies (e.g., breast and prostate cancers), dysregulated female hormone cascades also contribute to EC tumor progression, in association with misexpression of specific miRs.

\section{Epigenetic therapies for the management of ovarian \& endometrial cancers \\ DNA methylation \& HDAC inhibitors}

As DNA methylation and histone deacetylation are the two best characterized transcriptionally repressive epigenetic modifications, inhibitors of these repressors have been under study for several decades. Several agents have been discovered as DNMT inhibitors (DNMTIs), which reverse genomic methylation of 5-methylcytosine. Most of these are cytosine analogs that covalently and irreversibly bind to 


\begin{tabular}{|c|c|c|c|c|c|}
\hline $\operatorname{miR}(s)$ & $\begin{array}{l}\text { Up-/ } \\
\text { down- } \\
\text { regulated }\end{array}$ & $\begin{array}{l}\text { Possible } \\
\text { mechanism(s) }\end{array}$ & Potential targets & $\begin{array}{l}\text { Possible consequence(s) to } \\
\text { tumor progression }\end{array}$ & Ref. \\
\hline $10 a$ & Up & $\begin{array}{l}\text { Hypoxia and } \\
\text { retinoic acid } \\
\text { target }\end{array}$ & $\begin{array}{l}\text { USF2, HOXA1, HOXD10, HOXB1, } \\
\text { HOXB3, RB1CC1 and ribosomal } \\
\text { proteins (enhances translation) }\end{array}$ & Invasion, metastasis & [274-277] \\
\hline 31 & Up & Unknown & FOXCP2 and FOXP3 & Invasion/metastasis & [274] \\
\hline 96 & Up & $\begin{array}{l}\text { DNA } \\
\text { hypomethylation }\end{array}$ & CHES1, FOXO1 and FOXO3A & Inhibition of apoptosis & {$[170,274]$} \\
\hline 103 & Up & Unknown & 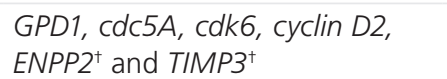 & $\begin{array}{l}\text { Motility, angiogenesis, cell cycle arrest } \\
\text { and hypoxia survival }\end{array}$ & {$[177,276]$} \\
\hline $106 a$ & Up & $\begin{array}{l}\text { Rearrangement } \\
\text { and c-myc target }\end{array}$ & 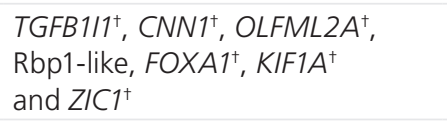 & $\begin{array}{l}\text { Tumor initiation and tumor } \\
\text { progression }\end{array}$ & {$[177,275]$} \\
\hline 107 & Up & $\begin{array}{l}\text { DNA } \\
\text { hypomethylation }\end{array}$ & ENPP2 ${ }^{\dagger}, C D K 2$ and $H I F 1 \alpha$ & Unknown & {$[177,277]$} \\
\hline $\begin{array}{l}141 \\
200 a, b \\
\text { and } c\end{array}$ & Up & Unknown & $\begin{array}{l}\text { ZEB1, ZEB2, TCF8, BAP1, GATA4 } \\
\text { and } J P H 4^{+}\end{array}$ & Unknown & {$[274,276]$} \\
\hline $142-5 p$ & Up & Unknown & $\begin{array}{l}E 2 F 7, E G R 3, I G F 1, \text { SOX11, SOX5 } \\
\text { and TGFBR2 }\end{array}$ & Unknown & {$[275]$} \\
\hline $\begin{array}{l}150 \text { and } \\
186\end{array}$ & Up & Unknown & $\begin{array}{l}R A B 32, P 2 X 7^{\dagger}, B M P 3, K L K 11 \\
c-M y b \text { and } F O X P 1\end{array}$ & $\begin{array}{l}\text { Oncogenic signaling and reduced } \\
\text { apoptotic potential }\end{array}$ & {$[171]$} \\
\hline 155 & Up & Unknown & $\begin{array}{l}\text { UBE2J1, DCAF7, RAB34 } \\
\text { and SH3BP4 }\end{array}$ & Unknown & {$[274]$} \\
\hline $181 a$ & Up & Unknown & $\begin{array}{l}\text { GPRASP1 }{ }^{\dagger}, T B L 1 X^{\dagger}, D P P 6^{\dagger}, K L F 2^{\dagger} \\
\text { HOXA11, GATA6, NLK and CDX2 }\end{array}$ & $\begin{array}{l}\text { Chemotherapy resistance, } \\
\text { dedifferentiation, cancer stemness } \\
\text { and cell proliferation }\end{array}$ & {$[177,256,276]$} \\
\hline 182,183 & Up & Copy gain & $\begin{array}{l}\text { FOXO1, FOXO3, CASP3, CASP2 } \\
\text { and Fas }\end{array}$ & $\begin{array}{l}\text { Dedifferentiation, reduced apoptotic } \\
\text { potential and migration }\end{array}$ & {$[170,177,274-276]$} \\
\hline 185 & Up & Copy gain & $\begin{array}{l}S L C 16 A 2, K L F 5^{\dagger} \text { and } \\
\text { protocadherin family }\end{array}$ & Loss of cell-cell adhesion & {$[177,278]$} \\
\hline $196 a$ & Up & IFN- $\beta$ target & $\begin{array}{l}\text { ANXA1, HOXB8, HOXA7, } \\
\text { HOXC8 and HOXD8 }\end{array}$ & $\begin{array}{l}\text { Reduced apoptotic potential and } \\
\text { dedifferentiation }\end{array}$ & {$[172]$} \\
\hline 203 & Up & $\begin{array}{l}\text { DNA } \\
\text { hypomethylation }\end{array}$ & $\begin{array}{l}\text { JPH4, ZIC1, CDK6, VIM, ABCE1, } \\
\text { SMYD3 and p63 }\end{array}$ & Unknown & {$[275,276]$} \\
\hline 205 & Up & Unknown & $\begin{array}{l}E 2 F 1, E R B B 3, J P H 4^{\dagger}, S 100 A 2^{\dagger} \\
\text { ZEB1 and } Z E B 2\end{array}$ & Unknown & {$[275,276]$} \\
\hline 210 & Up & $\begin{array}{l}\text { Hypoxia and } \\
\text { DNA } \\
\text { hypomethylation }\end{array}$ & $\begin{array}{l}\text { DCHS1 }{ }^{\dagger}, E N P P 2^{\dagger}, M Y H 11^{\dagger} \\
K C N M B 1^{\dagger}, M N T, B D N F \\
\text { and PTPN1 }\end{array}$ & $\begin{array}{l}\text { Oncogenic signaling and } \\
\text { cell migration }\end{array}$ & {$[177,274-276]$} \\
\hline 363 & Up & Unknown & $\begin{array}{l}\text { CUL3, CXCL5, AGGF1, CIT, } \\
\text { DUSP6 and EPS8 }\end{array}$ & $\begin{array}{l}\text { Unknown and anchorage } \\
\text { independence }\end{array}$ & {$[274,279]$} \\
\hline 423 & Up & Unknown & $\begin{array}{l}\text { DENND2 }{ }^{\dagger}, M Y L 9^{\dagger}, K L F 2^{\dagger} \\
\text { IGFBP } 68^{+} \text {and } C L K 3\end{array}$ & Unknown & {$[178]$} \\
\hline 449 & Up & Unknown & $\begin{array}{l}\text { WISP2, MUC5B, EFNB1 } \\
\text { and VAMP2 }\end{array}$ & Unknown & {$[274]$} \\
\hline $513 a-5 p$ & Up & Unknown & $\begin{array}{l}\text { CCRL1, MCHR2, CD274', RGS5 } \\
\text { and EPS8 }\end{array}$ & Represses IFN- $\gamma$-induced apoptosis & {$[275]$} \\
\hline 629 & Up & Unknown & $\begin{array}{l}\text { LRP6, TCF4, SEPT1, ZNF436 } \\
\text { and SLC1A7 }\end{array}$ & Unknown & {$[275]$} \\
\hline 1 & Down & Unknown & $\begin{array}{l}\text { c-Met, TIMP-3, TRIM2, ITGB3, } \\
\text { ZNF264 and WDFY1 }\end{array}$ & $\begin{array}{l}\text { Oncogenic signal transduction and } \\
\text { invasion/metastasis }\end{array}$ & {$[275,280]$} \\
\hline 26 family & Down & Unknown & $\begin{array}{l}\text { SMAD1, SOX2, BCl6, SMAD4, } \\
B C L 2 \text { and } K L F 4\end{array}$ & Inhibition of apoptosis & {$[174]$} \\
\hline
\end{tabular}


Table 4. Partial list of dysregulated miRs and their possible oncogenic roles, in endometrial cancer (cont.).

\begin{tabular}{|c|c|c|c|c|c|}
\hline $\operatorname{miR}(s)$ & $\begin{array}{l}\text { Up-/ } \\
\text { down- } \\
\text { regulated }\end{array}$ & $\begin{array}{l}\text { Possible } \\
\text { mechanism(s) }\end{array}$ & Potential targets & $\begin{array}{l}\text { Possible consequence(s) to } \\
\text { tumor progression }\end{array}$ & Ref. \\
\hline $29 b$ & Down & Unknown & $\begin{array}{l}\text { IGF1, MCl-1 and various } \\
\text { collagens }\end{array}$ & $\begin{array}{l}\text { Inhibition of apoptosis and } \\
\text { migration/invasion }\end{array}$ & [275] \\
\hline $30 c$ & Down & Unknown & $\begin{array}{l}\text { MYH11 } 1^{+}, G P R A S P 2^{+}, D D R 2^{+}, \\
\text {CKS2 and C5 }\end{array}$ & $\begin{array}{l}\text { Cell cycle dysregulation and } \\
\text { oncogenic signaling }\end{array}$ & {$[176]$} \\
\hline 101 & Down & Unknown & $\mathrm{COX} 2, E Z H 2$ & Cell proliferation and cancer stemness & [275] \\
\hline 125 & Down & Unknown & $\begin{array}{l}\text { LIN28, ERBB2, ERBB3, Akt3 } \\
\text { and ETS1 }\end{array}$ & $\begin{array}{l}\text { Oncogenic signaling and cancer } \\
\text { stemness }\end{array}$ & {$[175]$} \\
\hline $129-2$ & Down & DNA methylation & $\mathrm{SOX} 4^{+}$ & Migration and invasion & [173] \\
\hline $133 a, b$ & Down & Unknown & $P K M 2, M C l-1$ and $B C / 2 / 2$ & Inhibition of apoptosis & [275] \\
\hline $455-5 p$ & Down & Copy loss & $\begin{array}{l}\text { PP1R12A, KDR, SUZ12, FOXN3 } \\
\text { and PTPRJ }\end{array}$ & $\begin{array}{l}\text { Cancer stemness and oncogenic } \\
\text { signaling }\end{array}$ & {$[275,278]$} \\
\hline $654-3 p$ & Down & Unknown & $\begin{array}{l}\text { KLF12, SORBS1, WDR26, RNF145 } \\
\text { and AP1S3 }\end{array}$ & $\begin{array}{l}\text { Loss of cell adhesion, proliferation, } \\
\text { apoptosis inhibition and } \\
\text { invasion/metastasis }\end{array}$ & {$[168,175]$} \\
\hline 873 & Down & Unknown & $\begin{array}{l}\text { FOXK2, TBL1X, TMOD2, BMPR2, } \\
\text { SFRS1 and TAOK1 }\end{array}$ & Unknown & [275] \\
\hline $193 a, b$ & Down & DNA methylation & $\begin{array}{l}\text { KIT, RAMP1 }{ }^{\dagger}, T S P Y L 5^{\dagger}, E R B B 4 \\
R O B O 4^{+}, U P A \text { and } A B L 2\end{array}$ & $\begin{array}{l}\text { Oncogenic signaling and } \\
\text { invasion/metastasis? }\end{array}$ & {$[176,274]$} \\
\hline 204 & Down & Unknown & Ezrin, ESR1, CHD5 and CAMTA1 & $\begin{array}{l}\text { Cell proliferation, increased } \\
\mathrm{Ca}^{2+} \text { signaling }\end{array}$ & {$[274]$} \\
\hline 411 & Down & Unknown & $\begin{array}{l}\text { MAP3K1, SP2, CDH2, FOXO1, } \\
\text { SMAD4 and SET }\end{array}$ & Oncogenic signal transduction & [275] \\
\hline 424 & Down & PU.1 target & CCNE1, CCND1 and NFI-A & $\begin{array}{l}\text { Cell cycle dysregulation and } \\
\text { dedifferentiation }\end{array}$ & [275] \\
\hline $518 c$ & Down & Unknown & $\begin{array}{l}\text { ID-1, HOXA3, HOXC8, RAP1B, } \\
\text { ABCG2 and HLA-G }\end{array}$ & Chemotherapy resistance & {$[254,275,283]$} \\
\hline $\begin{array}{l}542-3 p \\
5 p\end{array}$ & Down & Unknown & $\begin{array}{l}\text { COX-2, HSPG2, ZNF618 } \\
\text { and CREB5 }\end{array}$ & $\begin{array}{l}\text { Inflammatory responses and } \\
\text { dedifferentiation }\end{array}$ & {$[275,284]$} \\
\hline 765 & Down & Copy loss & $\begin{array}{l}\text { KLK4, POU2F2, TIMP3, ADAM19 } \\
\text { and BCL6B }\end{array}$ & $\begin{array}{l}\text { Apoptosis inhibition and } \\
\text { invasion/metastasis }\end{array}$ & [275] \\
\hline 1226 & Down & Copy loss & MARCH9 and PPFIBP1 & Unknown & [275] \\
\hline
\end{tabular}

the active site of DNMTs, ultimately resulting in their cellular depletion [49]. The hypomethylating activity of these inhibitors is replication-dependent, requiring several cell divisions to complete the demethylation of each DNA strand [18]. The first FDA approved DNMTI was the ribonucleotide 5-azacytidine $\left(\mathrm{Vidaza}^{\circledR}\right.$,
Celgene Corp., NJ, USA), representing the first commissioned therapy for myelodysplastic syndrome [51].

In addition to azacytidine, its deoxyribose analog, 5-aza-2'-deoxycytidine (decitabine, Dacogen $^{\circledR}$, SuperGen, CA, USA; licensed to Eisai, NJ, USA), is also approved for the therapy 
of myelodysplastic syndrome [49,181]. Decitabine is a potent methylation inhibitor, effective at submicromolar concentrations and has been shown to elicit demethylation in numerous ovarian and EC cell lines, reversing the silencing of several TSGs [13,134,182]. Decitabine-mediated DNA demethylation also associates with reduced methylation at lysines 9 and 27 of histone H3, two other repressive chromatin 'marks' [114,183]. As decitabine is subject to intracellular deamination and aqueous instability (resulting in loss of hypomethylating activity), a more stable decitabine dinucleotide analog, SG-110 (SuperGen, CA, USA), has been developed that is resistant to cytidine deaminase and exhibits potent antigrowth effects against bladder cancer cells (with negligible toxicity) [184]. In addition to decitabine, our group has also examined another DNMTI, zebularine, demonstrating that this agent derepresses TSGs and potently inhibits the growth of several ovarian cancer cell lines [185]. In another preclinical study, short inhibitory RNA interference against DNMT1 and DNMT3b elicited DNA demethylation and gene derepression similar to (or greater than) deoxycytosine analogs [186] and subsequently, a Phase I clinical trial of a DNMT1 antisense oligonucleotide, MG98 (MethylGene, Quebec, Canada), demonstrated safety and biological activity of such an approach against various solid tumors (including ovarian cancer) [187]. Analogously, various rationally designed, non-nucleoside DNMTIs have also demonstrated potent downregulation of methyltransferase activity, silenced TSG reexpression and antigrowth effects in colon and hepatocullar carcinoma cells [188-190]. Another non-nucleoside agent, the antihypertensive vasodilator hydralazine, also possesses DNMT inhibitory activity and in a Phase II combination study with the HDAC inhibitor (HDACI) valproic acid and conventional chemotherapy, produced partial responses in three out of seven ovarian cancer patients [191].

As histone deacetylation is another transcriptional silencing mechanism, HDACIs can also relieve epigenetic gene repression. Numerous HDACIs, which antagonize the action of HDACs by chelation of an essential zinc ion cofactor [192], are now under extensive investigation, based on their abilities to selectively induce differentiation and apoptosis in tumor, but not normal cells [192]. One proposed mechanism for the cancer cell selectivity of HDACIs is the induction of checkpoint defects [193], and such an effect (G2 arrest followed by apoptosis) was recently demonstrated in platinum-resistant ovarian cancer cells [194]. Interestingly, while HDACIs potently induce histone hyperacetylation, their effects on nonhistone protein acetylation (including transcription factors, molecular chaperones, cargo transporters and cytoskeletal proteins) may play an even greater role in their antineoplastic activity $[192,195]$.

To date, HDACIs have demonstrated their greatest promise for the therapy of hematologic malignancies, with two HDACIs, suberoylanilide hydroxamic acid (vorinostat, Zolinza ${ }^{\circledR}$, Merck \& Co. NJ, USA) and depsipeptide (romidepsin, Istodax ${ }^{\circledR}$, Celgene Corp., NJ, USA), now approved for the therapy of cutaneous T-cell lymphoma [196]. In preclinical studies of ovarian and ECs, several HDACIs, including belinostat (PXD101), vorinostat and Scriptaid, demonstrated single-agent efficacy in inducing cytodifferentiation and apoptosis of cultured cells and mice xenografts [194,197-199]. Another HDACI, the short-chain fatty acid valproic acid (a well-established anticonvulsant), was also highly antiproliferative against human SKOV-3 ovarian cancer cells and HEC-1B EC cells, both in culture and in mouse xenografts [200].

Although there are no current clinical trials, several preclinical studies have demonstrated significant HDACI efficacy for EC. One natural HDACI, psammaplin A, present in marine sponges, upregulated the cell cycle regulator p21WAF1, while downregulating various cyclins and cyclin-dependent kinases, in Ishikawa EC cells, resulting in G2/G1 arrest and apoptosis [201]. In another study of Ishikawa EC xenografts of nude mice, the HDACI apicidin significantly reduced tumor size and expression of the angiogenesis marker VEGF [202], while the HDACI MS-275 similarly induced cell cycle arrest and apoptosis in four EC cell lines, while normal endometrial epithelial cells remained viable [203]. In other work, it was found that the HDACI oxamflatin and another natural HDACI, pterostilbene, induced apoptosis in both type I and type II EC cell lines [204], while the synthetic HDACI M344 similarly induced cell cycle arrest and apoptosis of Ishikawa EC and ovarian cancer SKOV-3 cells, with normal endometrial epithelial cells remaining viable at the same doses [205]. Interestingly, it appears that HDACIs may exert their anti-EC effects through repression of ER-target genes, while simultaneously stimulating target genes of the glucocorticoid receptor [206].

Despite the success of preclinical studies, a Phase II trial of monotherapeutic vorinostat for advanced ovarian cancer patients was well 
tolerated but demonstrated minimal clinical activity, with only one partial and two disease progression-free responses out of 21 patients [207]. However, a 21-patient ovarian cancer Phase II trial of the HDACI belinostat resulted in nine stable disease responses and one partial response [208]. Nonetheless, it is now widely believed that these agents will be most effective in combination with conventional chemotherapies $([18,49,51]$ and see following sections).

While HDACIs and DNMTIs have demonstrated clinical activity as single agent therapies for hematopoietic malignancies, DNA methylation and histone deacetylation often coordinately inhibit gene transcription (often in multiple-repressor protein complexes), and relief of both silencing mechanisms may be necessary for maximal gene derepression $[49,209]$. In ovarian cancer cells, it was found that treatment with a DNMTI/HDACI combination was synergistic for upregulation of the pro-apoptotic gene TMS1/ASC, in contrast to either agent alone [210]. A similar result was obtained for epigenetic derepression of the progesterone- $\mathrm{B}$ $(P R-B)$ gene in EC cells [211]. Using a microarray approach, we likewise demonstrated that a DNMTI/HDACI combined treatment of ovarian cancer cells elicited induction of a greater number of genes than either agent alone [212], similar to other preclinical studies showing DNMTII/HDACI co-treatment to additively or synergistically elicit TSG re-expression and tumor/cancer cell growth inhibition [213,214]. However, while a Phase I clinical trial combining the HDACI valproic acid and the DNMTI azacytidine for various solid tumors demonstrated safety, in vivo biological activity and stable disease in $25 \%$ of the enrolled patients, no partial or complete responses were observed [215]. Consequently, it is now widely held that epigenetic derepressive agents (singly or in combination) may be most effective in concert with conventional antineoplastic therapies $[10,13,49]$ (see next section).

\section{Epigenetic therapies for chemosensitization}

Epigenetic inhibitors (singly or in combination) also hold promise for resensitization of chemoresistant tumors, which is likely to be due to the restoration of drug response pathways. In preclinical studies, it was demonstrated that decitabine could resensitize platinum-resistant ovarian cancer cells and mouse xenografts to cisplatin, due to demethylation-induced hMLH1 re-expression [216], similar to work demonstrating cisplatin-chemosensitizing activity by the DNMTI zebularine and the HDACIs belinostat (PXD101) and valproic acid [10,198,217]. Similarly, our group demonstrated that a rationally designed HDACI, OSU-HDAC42, possessed greater cisplatin-resensitizing activity than vorinostat in chemoresistant ovarian cancer cells and mouse xenografts [218]. In EC cells, a combined DNMTI/HDACI treatment could restore $P R-B$ expression [211], suggesting possible sensitization to progestins, while the HDACI trichostatin A effectively resensitized aggressive Ark2 and KLE EC cells to paclitaxel [219]. Consequently, various clinical trials are now combining HDACIs with conventional chemotherapies, including Phase I/II ovarian cancer trials examining paclitaxel/carboplatin combined with either simultaneous or subsequent oral vorinostat (NCT00772798) [303] and vorinostat combined with carboplatin and gemcitabine (NCT00910000) [304].

DNA methyltransferase inhibitors are also now being examined in clinical trials in combination with conventional chemotherapies [181]. Discouragingly, one recent Phase I/II combinatorial ovarian cancer study, of decitabine paired with carboplatin, demonstrated no significant improvement over carboplatin alone [220,221]. However, another recently completed Phase IIa clinical trial of 5-azacytidine and carboplatin resulted in one complete, three partial and ten stable disease responses (of 29 total patients), with a 7.5-month average duration of response [222]. Similarly, our group recently completed a Phase I trial of low-dose decitabine (five consecutive-day regimen) paired with carboplatin, demonstrating acceptable tolerability of the combined regimen [17]. That regimen also demonstrated biological activity in vivo, as assessed by hypomethylation of genome-wide repetitive elements (in peripheral blood cells) and specific ovarian cancer-associated genes (in plasma, ascites or tumor) [17], resulting in one complete and six stable disease responses (of nine patients), with four patients remaining progression-free for 6 months [17]. The Phase II component of that study is now in progress (NCT00477386) [305].

As the microtubule-stabilizing drug paclitaxel, in addition to platinum drugs, is a common therapy for advanced stage ovarian cancers and ECs, epigenetic derepressive agents are also being examined for the possible reversal of taxane resistance. In several preclinical studies, vorinostat alone was found effective against paclitaxel -resistant ovarian cancer cells; however, its 
anti-tumor activity was substantially greater in combination with paclitaxel [223-225]. Similarly, in mice bearing EC cell (Ark2) tumor xenografts, the combination of trichostatin A with paclitaxel reduced tumor masses by $50 \%$ or more, while each agent alone resembled the control treatment [219]. Consequently, a recently completed Phase I ovarian cancer trial (NCT00421889) examined belinostat in combination with paclitaxel and carboplatin [306].

As noted above, combinations of epigenetic derepressive agents may elicit greater gene reactivation that single agents alone; those combinations can also be followed by conventional therapies. One combined treatment of decitabine and belinostat demonstrated significantly greater cisplatin sensitization of platinumresistant CP70 cell xenografts, in tumor-bearing mice, than either epigenetic therapy alone [226].
Similarly, in one Phase III ovarian cancer trial (NCT00533299), the DNMTI hydralazine is being combined with the HDACI valproic acid, with or without the topoisomerase inhibitor topotecan, while another Phase II trial examined four different chemotherapy regimens followed by daily hydralazine/valproic acid [307] In the latter study, of the seven ovarian cancer patients, three underwent partial responses, while four exhibited stable disease (using IGCG CA-125 criteria) [191]. Vidaza is also being examined in a Phase I/II ovarian cancer trial (NCT00529022) in combination with valproic acid and carboplatin [308].

In addition to reactivation of TSGs (and possible chemotherapy response cascades), DNMTIs and HDACIs have also been found to derepress various cancer/testis antigens (CTAs; components of the 'tumor recognition compex') [18].

\section{Executive summary}

\section{Ovarian cancer}

- Due to insufficient screening methods and ambiguity of early symptoms, serous ovarian cancer remains largely undiagnosed (>70\% of cases) prior to stage III or IV disease.

- Owing to the relative rarity of ovarian cancer (1 in 71 lifetime risk of incidence), any feasible screening method would require a sensitivity of $75 \%$ and a specificity of $99.6 \%$. While currently therapy response-approved biomarkers, cancer antigen-125 and human epididymis protein 4, fail to achieve such stringency, it is possible that combining these with epigenetic biomarkers may attain that degree of rigor.

\section{Endometrial cancer}

- Although the overall 5-year survival rate for endometrial cancer is $83 \%$, the mortality of this malignancy (for unknown reasons) has been steadily increasing for the past 20 years.

- Endometrial cancers are subcategorized into type I malignancies, which are less aggressive and largely characterized by aberrant DNA methylation-induced gene silencing, while the more aggressive type II malignancies are generally associated with genetic damage.

\section{Therapy resistance of ovarian \& endometrial cancer}

- While over $80 \%$ of advanced ovarian cancer patients respond to chemotherapies, over $70 \%$ of those first responders eventually relapse to terminal, drug-resistant malignancy. Similarly, while stage I and stage II endometrial cancers are largely curable, more advanced malignancies often progress to a chemo- and radio-resistant phenotype.

- A recent hypothesis for cancer drug resistance posits a failure of conventional chemotherapies to target cancer stem cells, multipotent progenitors entirely responsible for propagation of the malignancy and thus regrowth of a fully therapy-resistant tumor.

\section{Epigenetic alterations associated with ovarian \& endometrial carcinogenesis}

- Aberrant DNA methylation is widespread in ovarian and endometrial tumors, including global hypomethylation, hypermethylation-induced silencing of tumor suppressor genes and hypomethylation-associated upregulation of oncogenes. Many of these abnormally methylated genes associate with chemoresistance and metastasis.

- Owing to the frequency of distinct methylated loci in ovarian and endometrial cancers and the additional detection of methylated DNA in body fluids, these represent potential disease biomarkers for early detection, overall prognosis, chemoresponse and metastasis.

- Epigenetic aberrations in endometrial cancer are frequently associated with altered sex steroid signaling; anomalous steroid exposure may also associate with atypical gene imprinting in utero.

- Numerous epigenetic alterations are specific to ovarian and endometrial carcinomas and thus represent promising biomarkers for early detection, therapy response and prognosis. Moreover, ovarian steroids also regulate microRNA expression profiles in the endometrium, suggesting hormonal imbalances to contribute to the malignancy of this tissue.

- MicroRNA 'signatures' have now been shown to be remarkably specific for malignancies and malignancy subtypes/grades. Thus, microRNA assessment holds much potential as a diagnostic/prognostic tool.

\section{Epigenetic therapies for the management of ovarian \& endometrial cancers}

- While single-agent studies of epigenetic therapies have revealed some efficacy, single agents in fact hold much greater promise in combination with other inhibitors of other epigenetic events or in combination with conventional chemotherapies (i.e., resensitization).

- Multipotent, chemoresistant tumor progenitors (cancer stem cells) recently identified in ovarian and endometrial cancers could potentially be influenced by epigenetic therapies (e.g., DNA methyltransferase and histone deacetylase inhibitors) that have now been well-established as differentiating agents and could conceivably disrupt the undifferentiated phenotype of tumor-initiating cells. 
CTA proteins, expressed in male germ cells but normally silenced in adult tissues, are expressed in various malignancies as antigenic peptides copresented with HLA Class I/II molecules and thus may represent immunotherapy targets [227]. However, as CTA expression is often variable, due to epigenetic repression, more consistent re-expression can be achieved by DNMTIs and/or HDACIs [228]. Consequently, an ongoing Phase I ovarian cancer trial (NCT00887796) is investigating decitabine combined with liposomal doxorubicin and peptide vaccination for the CTA NY-ESO-1 [309], while two other trials (NCT00701298, NCT00886457, for unspecified cancers) are combining decitabine with IFN- $\alpha 2 b[310,311]$. Thus, in addition to tumor suppressor reactivation, epigenetic therapies may also hold promise in immunotherapy.

\section{Conclusion \& future perspective}

It is now well established that epigenetic aberrations occur very early in malignant transformation of the ovary and endometrium, raising the possibility of identifying chemopreventive compounds or reliable screening methods for women at high risk for these diseases. As methylated DNA sequences and miRs have been detected in body fluids of cancer patients, these may represent a less invasive and more achievable means of disease detection and prognosis. Silenced genes typically possess multiple repressive epigenetic modifications in their promoters and one recent

\section{Bibliography}

Papers of special note have been highlighted as:

- of interest

" " of considerable interest

1 Howe HL, Wu X, Ries LA et al: : Annual report to the nation on the status of cancer, 1975-2003, featuring cancer among U.S. Hispanic/Latino populations. Cancer 107(8), 1711-1742 (2006).

2 Chiaffarino F, Pelucchi C, Parazzini F et al.: Reproductive and hormonal factors and ovarian cancer. Ann. Oncol. 12(3), 337-341 (2001).

3 Bosetti C, Negri E, Trichopoulos D et al.: Long-term effects of oral contraceptives on ovarian cancer risk. Int. J. Cancer 102(3), 262-265 (2002).

4 Jemal A, Siegel R, Ward E et al.: Cancer Statistics, 2008. CA Cancer J. Clin. 58, 71-96 (2008).

5 Moore RG, MacLaughlan S, Bast RC Jr: Current state of biomarker development for clinical application in epithelial ovarian cancer. Gynecol. Oncol. 116(2), 240-245 (2010).

study demonstrated 15 distinct factors in an epigenetic silencing network in human cancer cells [229]. Consequently, it is believed that combinatorial therapies will be most effective for the re-expression of tumor suppressors, possibly to elicit resensitization to conventional chemotherapies. As polycomb repressive complexes likely mediate self-renewal of CSCs, targeting these epigenetic modifiers may be a highly effective means of managing gynecological tumors and cancer in general. Overall, an improved understanding of epigenetic mechanisms of ovarian and EC will lead to improved diagnosis and therapy and it is likely that in the near future, anticancer drug regimens will routinely include epigenetic therapies, possibly in conjunction with predictive epigenetic biomarkers, in individually tailored treatment regimens.

\section{Financial \& competing interests disclosure}

The authors gratefully acknowledge grant support from the USA NIH, National Cancer Institute awards CA085289, CA113001, CA133877 and the Walther Cancer Foundation (IN, USA). Daniela E Matei received research support from EISAI (Dacogen ${ }^{\circledR}$ ) for conducting the clinical trial discussed in this manuscript. The authors have no other relevant affiliations or financial involvement with any organization or entity with a financial interest in or financial conflict with the subject matter or materials discussed in the manuscript apart from those disclosed.

No writing assistance was utilized in the production of this manuscript.

6 Clarke-Pearson DL: Clinical practice. Screening for ovarian cancer. N. Engl. J. Med. 361(2), 170-177 (2009).

7 Rosenthal AN, Menon U, Jacobs IJ: Screening for ovarian cancer. Clin. Obstet. Gynecol. 49(3), 433-447 (2006).

8 Barker PE, Wagner PD, Stein SE, Bunk DM, Srivastava S, Omenn GS: Standards for plasma and serum proteomics in early cancer detection: a needs assessment report from the national institute of standards and technology - National Cancer Institute Standards, Methods, Assays, Reagents and Technologies Workshop, August 18-19, 2005. Clin. Chem. 52(9), 1669-1674 (2006).

9 Coombes KR, Morris JS, Hu J, Edmonson SR, Baggerly KA: Serum proteomics profiling - a young technology begins to mature. Nat. Biotechnol. 23(3), 291-292 (2005).

10 Balch C, Montgomery JS, Paik HI et al.: New anti-cancer strategies: epigenetic therapies and biomarkers. Front. Biosci. 10, 1897-1931 (2005).
11 Laird PW: The power and the promise of DNA methylation markers. Nat. Rev. Cancer 3(4), 253-266 (2003).

12 Balch C, Fang F, Matei DE, Huang TH, Nephew KP: Minireview: epigenetic changes in ovarian cancer. Endocrinology 150(9), 4003-4011 (2009).

- Recent comprehensive review of ovarian cancer epigenetic aberrations, including misexpressed microRNAs (miRs).

13 Balch C, Huang TH, Brown R, Nephew KP: The epigenetics of ovarian cancer drug resistance and resensitization. Am. J. Obstet. Gynecol. 191(5), 1552-1572 (2004).

14 Barton CA, Hacker NF, Clark SJ, O'Brien PM: DNA methylation changes in ovarian cancer: implications for early diagnosis, prognosis and treatment. Gynecol. Oncol. 109(1), 129-139 (2008).

15 Ozols RF: Systemic therapy for ovarian cancer: current status and new treatments. Semin. Oncol. 33(2 Suppl. 6), S3-S11 (2006). 
16 Yap TA, Carden CP, Kaye SB: Beyond chemotherapy: targeted therapies in ovarian cancer. Nat. Rev. Cancer 9(3), 167-181 (2009).

17 Fang F, Balch C, Schilder J et al.: A Phase I and pharmacodynamic study of decitabine in combination with carboplatin in patients with recurrent, platinum-resistant, epithelial ovarian cancer. Cancer (2010) (In press).

18 Yoo CB, Jones PA: Epigenetic therapy of cancer: past, present and future. 5(1), 37-50 (2006).

19 Sorosky JI: Endometrial cancer. Obstet. Gynecol. 111(2 Pt 1), 436-447 (2008).

20 Brown ML, Riley GF, Schussler N, Etzioni R: Estimating health care costs related to cancer treatment from SEER-Medicare data. Med. Care 40 (Suppl. 8), IV-104-IV-117 (2002).

21 Allard JE, Maxwell GL: Race disparities between black and white women in the incidence, treatment, and prognosis of endometrial cancer. Cancer Control 16(1), 53-56 (2009).

22 Santin AD, Bellone S, Siegel ER et al: Racial differences in the overexpression of epidermal growth factor type II receptor (HER $2 /$ neu): a major prognostic indicator in uterine serous papillary cancer. Am. J. Obstet. Gynecol. 192(3), 813-818 (2005).

23 Powell MA, Mutch DG, Rader JS, Herzog TJ, Huang TH, Goodfellow PJ: Ribosomal DNA methylation in patients with endometrial carcinoma: an independent prognostic marker. Cancer 94(11), 2941-2952 (2002).

" Highly significant finding relevant to race-related disparities in endometrial cancer prognosis.

24 Hecht JL, Mutter GL: Molecular and pathologic aspects of endometrial carcinogenesis. J. Clin. Oncol. 24(29), 4783-4791 (2006).

25 Bokhman JV: Two pathogenetic types of endometrial carcinoma. Gynecol. Oncol. 15 (1), 10-17 (1983).

26 Shang Y: Molecular mechanisms of oestrogen and SERMs in endometrial carcinogenesis. Nat. Rev. Cancer 6(5), 360-368 (2006).

27 Zhou XC, Dowdy SC, Podratz KC, Jiang SW: Epigenetic considerations for endometrial cancer prevention, diagnosis and treatment. Gynecol. Oncol. 107(1), 143-153 (2007).

28 Lee CM, Szabo A, Shrieve DC, Macdonald OK, Gaffney DK: Frequency and effect of adjuvant radiation therapy among women with stage I endometrial adenocarcinoma. JAMA 295(4), 389-397 (2006).
29 Carey MS, Gawlik C, Fung-Kee-Fung M, Chambers A, Oliver T: Systematic review of systemic therapy for advanced or recurrent endometrial cancer. Gynecol. Oncol. 101(1), 158-167 (2006).

30 Gadducci A, Tana R, Cosio S, Fanucchi A, Genazzani AR: Molecular target therapies in endometrial cancer: from the basic research to the clinic. Gynecol. Endocrinol. 24(5), 239-249 (2008).

31 Chaudhry P, Asselin E: Resistance to chemotherapy and hormone therapy in endometrial cancer. Endocr. Relat. Cancer 16(2), 363-380 (2009).

32 Decruze SB, Green JA: Hormone therapy in advanced and recurrent endometrial cancer: a systematic review. Int. J. Gynecol. Cancer 17(5), 964-978 (2007).

33 Mellor HR, Callaghan R: Resistance to chemotherapy in cancer: a complex and integrated cellular response. Pharmacology 81(4), 275-300 (2008).

34 Eckstein N, Servan K, Hildebrandt B et al.: Hyperactivation of the insulin-like growth factor receptor I signaling pathway is an essential event for cisplatin resistance of ovarian cancer cells. Cancer Res. 69(7), 2996-3003 (2009).

35 Lu L, Katsaros D, de la Longrais IA, Sochirca O, Yu H: Hypermethylation of let-7a-3 in epithelial ovarian cancer is associated with low insulin-like growth factorII expression and favorable prognosis. Cancer Res. 67(21), 10117-10122 (2007).

36 Wiley A, Katsaros D, Chen H et al.: Aberrant promoter methylation of multiple genes in malignant ovarian tumors and in ovarian tumors with low malignant potential. Cancer 107(2), 299-308 (2006).

37 Zhou BB, Zhang H, Damelin M, Geles KG, Grindley JC, Dirks PB: Tumour-initiating cells: challenges and opportunities for anticancer drug discovery. Nat. Rev. Drug Discov. 8(10), 806-823 (2009).

- Recent review highlighting the controversies and possible modifications to the tumor stem cell hypothesis.

38 Dean M, Fojo T, Bates S: Tumour stem cells and drug resistance. Nat. Rev. Cancer 5(4), 275-284 (2005).

39 Zhang S, Balch C, Chan MW et al.: Identification and characterization of ovarian cancer-initiating cells from primary human tumors. Cancer Res. 68(11), 4311-4320 (2008).

40 Alvero AB, Chen R, Fu HH et al: Molecular phenotyping of human ovarian cancer stem cells unravels the mechanisms for repair and chemoresistance. Cell Cycle 8(1), 158-166 (2009).
41 Baba T, Convery PA, Matsumura N et al.: Epigenetic regulation of CD133 and tumorigenicity of $\mathrm{CD} 133^{+}$ovarian cancer cells. Oncogene 28(2), 209-218 (2009).

42 Curley MD, Therrien VA, Cummings CL et al:: CD133 expression defines a tumor initiating cell population in primary human ovarian cancer. Stem Cells 27(12), 2875-2883 (2009).

43 Friel AM, Sergent PA, Patnaude C et al.: Functional analyses of the cancer stem cell-like properties of human endometrial tumor initiating cells. Cell Cycle 7(2), 242-249 (2008).

44 Hubbard SA, Friel AM, Kumar B, Zhang L, Rueda BR, Gargett CE: Evidence for cancer stem cells in human endometrial carcinoma. Cancer Res. 69(21), 8241-8248 (2009).

45 Rutella S, Bonanno G, Procoli A et al.: Cells with characteristics of cancer stem/progenitor cells express the CD133 antigen in human endometrial tumors. Clin. Cancer Res. 15(13), 4299-4311 (2009).

46 Boyer LA, Plath K, Zeitlinger J et al.: Polycomb complexes repress developmental regulators in murine embryonic stem cells. Nature 441(7091), 349-353 (2006).

47 Bibikova M, Chudin E, Wu B et al:: Human embryonic stem cells have a unique epigenetic signature. Genome Res. 16(9), 1075-1083 (2006).

48 Sasaki H, Matsui Y: Epigenetic events in mammalian germ-cell development: reprogramming and beyond. Nat. Rev. Genet. 9(2), 129-140 (2008).

49 Jones PA, Baylin SB: The epigenomics of cancer. Cell 128(4), 683-692 (2007).

50 Bestor TH: The host defence function of genomic methylation patterns. Novartis Found. Symp. 214, 187-195; discussion 195-189, 228-232 (1998).

51 Esteller M: Epigenetics in cancer. N. Engl. J. Med. 358(11), 1148-1159 (2008).

52 Cedar H, Bergman Y: Linking DNA methylation and histone modification: patterns and paradigms. Nat. Rev. Genet. 10(5), 295-304 (2009).

53 Campos EI, Reinberg D: Histones: annotating chromatin. Annu. Rev. Genet. 43, 559-599 (2009).

54 Mikkelsen TS, Ku M, Jaffe DB et al.: Genome-wide maps of chromatin state in pluripotent and lineage-committed cells. Nature 448(7153), 553-560 (2007).

55 Gan Q, Yoshida T, McDonald OG, Owens GK: Concise review: epigenetic mechanisms contribute to pluripotency and cell lineage determination of embryonic stem cells. Stem Cells 25(1), 2-9 (2007). 
56 Ohm JE, McGarvey KM, Yu X et al:: A stem cell-like chromatin pattern may predispose tumor suppressor genes to DNA hypermethylation and heritable silencing. Nat. Genet. 39(2), 237-242 (2007).

57 Rountree MR, Bachman KE, Herman JG, Baylin SB: DNA methylation, chromatin inheritance, and cancer. Oncogene 20(24), 3156-3165 (2001)

58 Lee MG, Wynder C, Bochar DA, Hakimi MA, Cooch N, Shiekhattar R: Functional interplay between histone demethylase and deacetylase enzymes. Mol. Cell Biol. 26(17), 6395-6402 (2006).

59 Sparmann A, van Lohuizen M: Polycomb silencers control cell fate, development and cancer. Nat. Rev. Cancer 6(11), 846-856 (2006).

60 Schickel R, Boyerinas B, Park SM, Peter ME: MicroRNAs: key players in the immune system, differentiation, tumorigenesis and cell death. Oncogene 27(45), 5959-5974 (2008).

61 Bartel DP: MicroRNAs: target recognition and regulatory functions. Cell 136(2), 215-233 (2009).

62 Friedman JM, Jones PA: MicroRNAs: critical mediators of differentiation, development and disease. Swiss Med. Wkly 139(33-34), 466-472 (2009).

63 Asli NS, Pitulescu ME, Kessel M: MicroRNAs in organogenesis and disease. Curr. Mol. Med. 8(8), 698-710 (2008).

64 Kumar MS, Lu J, Mercer KL, Golub TR, Jacks $T$ : Impaired microRNA processing enhances cellular transformation and tumorigenesis. Nat. Genet. 39(5), 673-677 (2007).

65 Kent OA, Mendell JT: A small piece in the cancer puzzle: microRNAs as tumor suppressors and oncogenes. Oncogene 25(46), 6188-6196 (2006).

66 Krutzfeldt J, Rajewsky N, Braich R et al.: Silencing of microRNAs in vivo with 'antagomirs'. Nature 438(7068), 685-689 (2005).

67 Bonauer A, Carmona G, Iwasaki M et al.: MicroRNA-92a controls angiogenesis and functional recovery of ischemic tissues in mice. Science 324(5935), 1710-1713 (2009).

68 Chan TA, Glockner S, Yi JM et al.: Convergence of mutation and epigenetic alterations identifies common genes in cancer that predict for poor prognosis. PLoS Med. 5(5), E114 (2008).

69 Kurose K, Zhou XP, Araki T, Cannistra SA, Maher ER, Eng C: Frequent loss of PTEN expression is linked to elevated phosphorylated Akt levels, but not associated with p27 and cyclin D1 expression, in primary epithelial ovarian carcinomas. Am. J. Pathol. 158(6), 2097-2106 (2001)
70 Fiegl H, Windbichler G, Mueller-Holzner E et al:: HOXA11 DNA methylation - a novel prognostic biomarker in ovarian cancer. Int. J. Cancer 123(3), 725-729 (2008).

71 Widschwendter M, Apostolidou S, Jones AA et al.: HOXA methylation in normal endometrium from premenopausal women is associated with the presence of ovarian cancer: a proof of principle study. Int. J. Cancer 125(9), 2214-2218 (2009).

72 Barbolina MV, Adley BP, Kelly DL et al.: Downregulation of connective tissue growth factor by three-dimensional matrix enhances ovarian carcinoma cell invasion. Int. J. Cancer 125(4), 816-825 (2009).

73 Kikuchi R, Tsuda H, Kanai Y et al.: Promoter hypermethylation contributes to frequent inactivation of a putative conditional tumor suppressor gene connective tissue growth factor in ovarian cancer. Cancer Res. 67(15), 7095-7105 (2007).

74 Barton CA, Gloss BS, Qu W et al.: Collagen and calcium-binding EGF domains 1 is frequently inactivated in ovarian cancer by aberrant promoter hypermethylation and modulates cell migration and survival. Br. J. Cancer 102(1), 87-96 (2010).

75 Rathi A, Virmani AK, Schorge JO et al.: Methylation profiles of sporadic ovarian tumors and nonmalignant ovaries from high-risk women. Clin. Cancer Res. 8(11), 3324-3331 (2002).

76 Makarla PB, Saboorian MH, Ashfaq R et al.: Promoter hypermethylation profile of ovarian epithelial neoplasms. Clin. Cancer Res. 11(15), 5365-5369 (2005).

77 Sawada K, Mitra AK, Radjabi AR et al.: Loss of E-cadherin promotes ovarian cancer metastasis via $\alpha 5$-integrin, which is a therapeutic target. Cancer Res. 68(7), 2329-2339 (2008).

78 Issa JP: CpG island methylator phenotype in cancer. Nat. Rev. Cancer 4(12), 988-993 (2004).

79 Teodoridis JM, Hardie C, Brown R: CpG island methylator phenotype (CIMP) in cancer: causes and implications. Cancer Lett. 268(2), 177-186 (2008).

80 Ahluwalia A, Hurteau JA, Bigsby RM, Nephew KP: DNA methylation in ovarian cancer. II. Expression of DNA methyltransferases in ovarian cancer cell lines and normal ovarian epithelial cells. Gynecol. Oncol. 82(2), 299-304 (2001).

81 Ehrlich M, Woods CB, Yu MC et al. Quantitative analysis of associations between DNA hypermethylation, hypomethylation, and DNMT RNA levels in ovarian tumors. Oncogene 25(18), 2636-2645 (2006).
82 Strathdee G, Appleton K, Illand M et al.: Primary ovarian carcinomas display multiple methylator phenotypes involving known tumor suppressor genes. Am. J. Pathol. 158(3), 1121-1127 (2001).

83 Furlan D, Carnevali I, Marcomini B et al.: The high frequency of de novo promoter methylation in synchronous primary endometrial and ovarian carcinomas. Clin. Cancer Res. 12(11 Pt 1), 3329-3336 (2006).

84 Ahluwalia A, Yan P, Hurteau JA et al.: DNA methylation and ovarian cancer. I. Analysis of CpG island hypermethylation in human ovarian cancer using differential methylation hybridization. Gynecol. Oncol. 82(2), 261-268 (2001).

85 Wei SH, Balch C, Paik HH et al:: Prognostic DNA methylation biomarkers in ovarian cancer. Clin. Cancer Res. 12(9), 2788-2794 (2006).

86 Wei SH, Chen CM, Strathdee G et al:: Methylation microarray analysis of late-stage ovarian carcinomas distinguishes progressionfree survival in patients and identifies candidate epigenetic markers. Clin. Cancer Res. 8(7), 2246-2252 (2002).

=- First assessment of genome-wide DNA methylation alterations in ovarian cancer, as a biomarker signature for disease outcome (e.g., progression-free survival).

87 Ibanez de Caceres I, Battagli C, Esteller M et al.: Tumor cell-specific $B R C A 1$ and RASSF1A hypermethylation in serum, plasma, and peritoneal fluid from ovarian cancer patients. Cancer Res. 64(18), 6476-6481 (2004).

- First report of DNA-methylated genes in body fluids of ovarian cancer patients, thus representing practical utility as disease biomarkers.

88 Gifford G, Paul J, Vasey PA, Kaye SB, Brown R: The acquisition of hMLH1 methylation in plasma DNA after chemotherapy predicts poor survival for ovarian cancer patients. Clin. Cancer Res. 10(13), 4420-4426 (2004)

89 Watanabe $\mathrm{Y}$, Ueda $\mathrm{H}$, Etoh $\mathrm{T}$ et al: : A change in promoter methylation of $\mathrm{hMLH} 1$ is a cause of acquired resistance to platinum-based chemotherapy in epithelial ovarian cancer. Anticancer Res. 27(3B), 1449-1452 (2007).

90 Helleman J, van Staveren IL, Dinjens WN et al:: Mismatch repair and treatment resistance in ovarian cancer. BMC Cancer 6, 201 (2006).

91 Nicholson LJ, Smith PR, Hiller L et al.: Epigenetic silencing of argininosuccinate synthetase confers resistance to platinuminduced cell death but collateral sensitivity to arginine auxotrophy in ovarian cancer. Int. J. Cancer 125(6), 1454-1463 (2009). 
92 Yap OW, Bhat G, Liu L, Tollefsbol TO: Epigenetic modifications of the estrogen receptor $\beta$ gene in epithelial ovarian cancer cells. Anticancer Res. 29(1), 139-144 (2009).

93 Su HY, Lai HC, Lin YW et al.: Epigenetic silencing of SFRP5 is related to malignant phenotype and chemoresistance of ovarian cancer through Wnt signaling pathway. Int. J. Cancer DOI: 10.1002/ijc. 25083 (2009) (Epub ahead of print).

94 Strathdee G, MacKean MJ, Illand M, Brown R: A role for methylation of the $h M L H 1$ promoter in loss of $h M L H 1$ expression and drug resistance in ovarian cancer. Oncogene 18(14), 2335-2341 (1999).

95 Strathdee G, Vass JK, Oien KA, Siddiqui N, Curto-Garcia J, Brown R: Demethylation of the $M C J$ gene in stage III/IV epithelial ovarian cancer and response to chemotherapy. Gynecol. Oncol. 97(3), 898-903 (2005).

96 Hatle KM, Neveu W, Dienz O et al.: Methylation-controlled J protein promotes c-Jun degradation to prevent ABCB1 transporter expression. Mol. Cell Biol. 27(8), 2952-2966 (2007).

97 Song J, Shih Ie M, Chan DW, Zhang Z: Suppression of annexin A11 in ovarian cancer: implications in chemoresistance. Neoplasia 11(6), 605-614 (2009).

98 Widschwendter M, Jiang G, Woods C et al.: DNA hypomethylation and ovarian cancer biology. Cancer Res. 64(13), 4472-4480 (2004).

99 Shao C, Lacey M, Dubeau L, Ehrlich M: Hemimethylation footprints of DNA demethylation in cancer. Epigenetics 4(3), 165-175 (2009).

100 Pattamadilok J, Huapai N, Rattanatanyong P et al.: LINE-1 hypomethylation level as a potential prognostic factor for epithelial ovarian cancer. Int. J. Gynecol. Cancer 18(4), 711-717 (2008).

101 Lee PS, Teaberry VS, Bland AE et al.: Elevated MAL expression is accompanied by promoter hypomethylation and platinum resistance in epithelial ovarian cancer. Int. J. Cancer 126(6), 1378-1389 (2010).

102 Litkouhi B, Kwong J, Lo CM et al.: Claudin-4 overexpression in epithelial ovarian cancer is associated with hypomethylation and is a potential target for modulation of tight junction barrier function using a C-terminal fragment of Clostridium perfringens enterotoxin. Neoplasia 9(4), 304-314 (2007).

103 Woloszynska-Read A, James SR, Link PA, Yu J, Odunsi K, Karpf AR: DNA methylation-dependent regulation of BORIS/CTCFL expression in ovarian cancer. Cancer Immun. 7, 21 (2007).
104 Bram EE, Stark M, Raz S, Assaraf YG: Chemotherapeutic drug-induced ABCG2 promoter demethylation as a novel mechanism of acquired multidrug resistance. Neoplasia 11(12), 1359-1370 (2009).

105 Izutsu N, Maesawa C, Shibazaki M et al: Epigenetic modification is involved in aberrant expression of class III $\beta$-tubulin, TUBB3, in ovarian cancer cells. Int. J. Oncol. 32(6), 1227-1235 (2008).

106 Gupta A, Godwin AK, Vanderveer L, Lu A, Liu J: Hypomethylation of the synuclein $\gamma$ gene $\mathrm{CpG}$ island promotes its aberrant expression in breast carcinoma and ovarian carcinoma. Cancer Res. 63(3), 664-673 (2003).

107 Rose SL, Fitzgerald MP, White NO et al.: Epigenetic regulation of maspin expression in human ovarian carcinoma cells. Gynecol. Oncol. 102(2), 319-324 (2006).

108 Honda H, Pazin MJ, D’Souza T, Ji H, Morin PJ: Regulation of the CLDN3 gene in ovarian cancer cells. Cancer Biol. Ther. 6(11), 1733-1742 (2007).

109 Choi YL, Kim J, Kwon MJ et al.: Expression profile of tight junction protein claudin 3 and claudin 4 in ovarian serous adenocarcinoma with prognostic correlation. Histol. Histopathol. 22(11), 1185-1195 (2007).

110 Weichert W, Denkert C, Noske A et al.: Expression of class I histone deacetylases indicates poor prognosis in endometrioid subtypes of ovarian and endometrial carcinomas. Neoplasia 10(9), 1021-1027 (2008).

111 Caslini C, Capo-chichi CD, Roland IH, Nicolas E, Yeung AT, Xu XX: Histone modifications silence the GATA transcription factor genes in ovarian cancer. Oncogene 25(39), 5446-5461 (2006).

112 Strait KA, Dabbas B, Hammond EH, Warnick CT, Iistrup SJ, Ford CD: Cell cycle blockade and differentiation of ovarian cancer cells by the histone deacetylase inhibitor trichostatin A are associated with changes in $\mathrm{p} 21, \mathrm{Rb}$, and Id proteins. Mol. Cancer Ther. 1(13), 1181-1190 (2002).

113 Kwon MJ, Kim SS, Choi YL et al: Derepression of CLDN3 and CLDN4 during ovarian tumorigenesis is associated with loss of repressive histone modifications. Carcinogenesis DOI:10.1093/carcin/bgp336 (2010) (Epub ahead of print).

114 Abbosh PH, Montgomery JS, Starkey JA et al:: Dominant-negative histone $\mathrm{H} 3$ lysine 27 mutant derepresses silenced tumor suppressor genes and reverses the drugresistant phenotype in cancer cells. Cancer Res. 66(11), 5582-5591 (2006).
115 Merritt WM, Lin YG, Han LY et al.: Dicer, Drosha, and outcomes in patients with ovarian cancer. N. Engl. J. Med. 359(25), 2641-2650 (2008).

- Striking report demonstrating the prognostic tumor suppressor significance of proper miR processing in ovarian cancer.

116 Pampalakis G, Diamandis EP, Katsaros D, Sotiropoulou G: Down-regulation of dicer expression in ovarian cancer tissues. Clin. Biochem. 43(3), 324-327 (2010).

117 Zhang L, Volinia S, Bonome T et al: Genomic and epigenetic alterations deregulate microRNA expression in human epithelial ovarian cancer. Proc. Natl Acad. Sci. USA 105(19), 7004-7009 (2008).

- Notable report demonstrates integration of genetic and epigenetic lesions with the dysregulation of miR expression in ovarian cancer.

118 Laios A, O'Toole S, Flavin R et al:: Potential role of miR-9 and miR-223 in recurrent ovarian cancer. Mol. Cancer 7, 35 (2008).

119 Zhang L, Huang J, Yang $N$ et al.: microRNAs exhibit high frequency genomic alterations in human cancer. Proc. Natl Acad. Sci. USA 103(24), 9136-9141 (2006).

120 Faggad A, Budczies J, Tchernitsa O et al.: Prognostic significance of Dicer expression in ovarian cancer-link to global microRNA changes and oestrogen receptor expression. J. Pathol. 220 (3), 382-391 (2010).

121 Brueckner B, Stresemann C, Kuner R et al.: The human let-7a-3 locus contains an epigenetically regulated microRNA gene with oncogenic function. Cancer Res. 67(4), 1419-1423 (2007).

122 Lee $\mathrm{CH}$, Subramanian S, Beck AH et al: MicroRNA profiling of BRCA1/2 mutationcarrying and non-mutation-carrying high-grade serous carcinomas of ovary. PLoS One 4(10), E7314 (2009).

123 Calin GA, Croce CM: MicroRNA signatures in human cancers. Nat. Rev. Cancer 6(11), 857-866 (2006).

124 Bhattacharya R, Nicoloso M, Arvizo R et al: MiR-15a and MiR-16 control Bmi-1 expression in ovarian cancer. Cancer Res. 69(23), 9090-9095 (2009).

125 Yang H, Kong W, He L et al.: MicroRNA expression profiling in human ovarian cancer: miR-214 induces cell survival and cisplatin resistance by targeting PTEN. Cancer Res. 68(2), 425-433 (2008).

126 Iorio MV, Visone R, Di Leva G et al.: MicroRNA signatures in human ovarian cancer. Cancer Res. 67(18), 8699-8707 (2007). 
127 Varambally S, Cao Q, Mani RS et al.: Genomic loss of microRNA-101 leads to overexpression of histone methyltransferase EZH2 in cancer. Science 322(5908), 1695-1699 (2008).

128 Dahiya N, Sherman-Baust CA, Wang TL et al:: MicroRNA expression and identification of putative miRNA targets in ovarian cancer. PLoS One 3(6), E2436 (2008).

129 Nam EJ, Yoon H, Kim SW et al.: MicroRNA expression profiles in serous ovarian carcinoma. Clin. Cancer Res. 14(9), 2690-2695 (2008).

130 Eitan R, Kushnir M, Lithwick-Yanai G et al.: Tumor microRNA expression patterns associated with resistance to platinum based chemotherapy and survival in ovarian cancer patients. Gynecol. Oncol. 114(2), 253-259 (2009).

131 Hu X, Macdonald DM, Huettner PC et al.: A miR-200 microRNA cluster as prognostic marker in advanced ovarian cancer. Gynecol. Oncol. 114(3), 457-464 (2009).

132 Shimono Y, Zabala M, Cho RW et al: Downregulation of miRNA-200c links breast cancer stem cells with normal stem cells. Cell 138(3), 592-603 (2009).

133 Campan M, Weisenberger DJ, Laird PW: DNA methylation profiles of female steroid hormone-driven human malignancies. Curr. Top. Microbiol. Immunol. 310, 141-178 (2006).

134 Sasaki M, Kaneuchi M, Fujimoto S, Tanaka Y, Dahiya R: Hypermethylation can selectively silence multiple promoters of steroid receptors in cancers. Mol. Cell Endocrinol. 202(1-2), 201-207 (2003).

135 Kang S, Kim JW, Kang GH et al.: Comparison of DNA hypermethylation patterns in different types of uterine cancer: cervical squamous cell carcinoma, cervical adenocarcinoma and endometrial adenocarcinoma. Int. J. Cancer 118(9), 2168-2171 (2006).

136 Yanokura M, Banno K, Susumu N et al.: Hypermethylation in the 16 promoter region in the carcinogenesis of endometrial cancer in Japanese patients. Anticancer Res. 26(2A), 851-856 (2006).

137 Wong YF, Chung TK, Cheung TH et al: Methylation of p16INK4A in primary gynecologic malignancy. Cancer Lett. 136(2), 231-235 (1999).

138 Whitcomb BP, Mutch DG, Herzog TJ, Rader JS, Gibb RK, Goodfellow PJ: Frequent HOXA11 and THBS2 promoter methylation, and a methylator phenotype in endometrial adenocarcinoma. Clin. Cancer Res. 9(6), 2277-2287 (2003).

139 Esteller M, Fraga MF, Guo M et al.: DNA methylation patterns in hereditary human cancers mimic sporadic tumorigenesis. Hum. Mol. Genet. 10(26), 3001-3007 (2001).
140 Yeh KT, Yang MY, Liu TC et al.: Abnormal expression of period 1 (PER1) in endometrial carcinoma. J. Pathol. 206(1), 111-120 (2005).

141 Gurin CC, Federici MG, Kang L, Boyd J: Causes and consequences of microsatellite instability in endometrial carcinoma. Cancer Res. 59(2), 462-466 (1999).

142 Jacinto FV, Esteller M: Mutator pathways unleashed by epigenetic silencing in human cancer. Mutagenesis 22(4), 247-253 (2007).

143 Rimel BJ, Huettner P, Powell MA, Mutch DG, Goodfellow PJ: Absence of MGMT promoter methylation in endometrial cancer. Gynecol. Oncol. 112(1), 224-228 (2009).

144 Loeb LA, Bielas JH, Beckman RA: Cancers exhibit a mutator phenotype: clinical implications. Cancer Res. 68(10), 3551-3557; discussion 3557 (2008).

145 Zighelboim I, Goodfellow PJ, Gao F et al. Microsatellite instability and epigenetic inactivation of MLH1 and outcome of patients with endometrial carcinomas of the endometrioid type. J. Clin. Oncol. 25(15), 2042-2048 (2007).

146 Salvesen HB, MacDonald N, Ryan A et al.: PTEN methylation is associated with advanced stage and microsatellite instability in endometrial carcinoma. Int. J. Cancer 91(1), 22-26 (2001).

147 Shibata D, Mori Y, Cai K et al.: RAB32 hypermethylation and microsatellite instability in gastric and endometrial adenocarcinomas. Int. J. Cancer 119(4), 801-806 (2006).

148 Yamaguchi S, Asanoma K, Takao T, Kato K, Wake N: Homeobox gene HOPX is epigenetically silenced in human uterine endometrial cancer and suppresses estrogen-stimulated proliferation of cancer cells by inhibiting serum response factor. Int. J. Cancer 124(11), 2577-2588 (2009).

149 Zysman M, Saka A, Millar A, Knight J, Chapman W, Bapat B: Methylation of adenomatous polyposis coli in endometrial cancer occurs more frequently in tumors with microsatellite instability phenotype. Cancer Res. 62(13), 3663-3666 (2002).

150 Zighelboim I, Goodfellow PJ, Schmidt AP et al:: Differential methylation hybridization array of endometrial cancers reveals two novel cancer-specific methylation markers. Clin. Cancer Res. 13(10), 2882-2889 (2007).

151 Varley KE, Mutch DG, Edmonston TB, Goodfellow PJ, Mitra RD: Intra-tumor heterogeneity of MLH1 promoter methylation revealed by deep single molecule bisulfite sequencing. Nucleic Acids Res. 37(14), 4603-4612 (2009).
152 Risinger JI, Maxwell GL, Chandramouli GV et al: : Gene expression profiling of microsatellite unstable and microsatellite stable endometrial cancers indicates distinct pathways of aberrant signaling. Cancer Res. 65(12), 5031-5037 (2005).

153 Katoh M: WNT signaling pathway and stem cell signaling network. Clin. Cancer Res. 13(14), 4042-4045 (2007).

154 Baylin SB, Ohm JE: Epigenetic gene silencing in cancer - a mechanism for early oncogenic pathway addiction? Nat. Rev. Cancer 6(2), 107-116 (2006).

155 Shapiro S, Kaufman DW, Slone D et al.: Recent and past use of conjugated estrogens in relation to adenocarcinoma of the endometrium. N. Engl. J. Med. 303(9), 485-489 (1980).

156 Kumar NS, Richer J, Owen G, Litman E, Horwitz KB, Leslie KK: Selective downregulation of progesterone receptor isoform $\mathrm{B}$ in poorly differentiated human endometrial cancer cells: implications for unopposed estrogen action. Cancer Res. 58(9), 1860-1865 (1998).

157 Clarke CL, Sutherland RL: Progestin regulation of cellular proliferation. Endocr. Rev. 11(2), 266-301 (1990).

158 Uharcek P: Prognostic factors in endometrial carcinoma. J. Obstet. Gynaecol. Res. 34(5), 776-783 (2008)

159 Sasaki M, Kotcherguina L, Dharia A, Fujimoto S, Dahiya R: Cytosine-phosphoguanine methylation of estrogen receptors in endometrial cancer. Cancer Res. 61(8), 3262-3266 (2001).

160 Maeda K, Tsuda H, Hashiguchi Y et al.: Relationship between $\mathrm{p} 53$ pathway and estrogen receptor status in endometrioid-type endometrial cancer. Hum. Pathol. 33(4), 386-391 (2002).

161 Wu H, Chen Y, Liang J et al.: Hypomethylation-linked activation of PAX2 mediates tamoxifen-stimulated endometrial carcinogenesis. Nature 438(7070), 981-987 (2005).

162 Newbold RR, Padilla-Banks E, Jefferson WN: Adverse effects of the model environmental estrogen diethylstilbestrol are transmitted to subsequent generations. Endocrinology 147(Suppl. 6), S11-S17 (2006).

163 Li S, Washburn KA, Moore R et al:: Developmental exposure to diethylstilbestrol elicits demethylation of estrogen-responsive lactoferrin gene in mouse uterus. Cancer Res. 57(19), 4356-4359 (1997).

164 Liu JR, Opipari AW, Tan L et al.: Dysfunctional apoptosome activation in ovarian cancer: implications for chemoresistance. Cancer Res. 62(3), 924-931 (2002). 
165 Li AJ, Baldwin RL, Karlan BY: Estrogen and progesterone receptor subtype expression in normal and malignant ovarian epithelial cell cultures. Am. J. Obstet. Gynecol. 189(1), 22-27 (2003).

166 Gargett CE: Identification and characterisation of human endometrial stem/progenitor cells. Aust. NZ J. Obstet. Gynaecol. 46(3), 250-253 (2006).

167 Chan RW, Gargett CE: Identification of label-retaining cells in mouse endometrium. Stem Cells 24(6), 1529-1538 (2006).

168 Kim JY, Tavare S, Shibata D: Counting human somatic cell replications: methylation mirrors endometrial stem cell divisions. Proc. Natl Acad. Sci. USA 102(49), 17739-17744 (2005).

169 Melo SA, Ropero S, Moutinho C et al:: A TARBP2 mutation in human cancer impairs microRNA processing and DICERI function. Nat. Genet. 41(3), 365-370 (2009).

170 Myatt SS, Wang J, Monteiro LJ et al.: Definition of microRNAs that repress expression of the tumor suppressor gene FOXO1 in endometrial cancer. Cancer Res. 70 (1), 367-377 (2010).

171 Zhou L, Qi X, Potashkin JA, AbdulKarim FW, Gorodeski GI: MicroRNAs miR-186 and miR-150 down-regulate expression of the pro-apoptotic purinergic P2X7 receptor by activation of instability sites at the 3 -untranslated region of the gene that decrease steady-state levels of the transcript. J. Biol. Chem. 283(42), 28274-28286 (2008).

172 Luthra R, Singh RR, Luthra MG et al.: MicroRNA-196a targets annexin A1: a microRNA-mediated mechanism of annexin A1 downregulation in cancers. Oncogene 27(52), 6667-6678 (2008).

173 Huang YW, Liu JC, Deatherage DE et al.: Epigenetic repression of microRNA-129-2 leads to overexpression of SOX4 oncogene in endometrial cancer. Cancer Res. 69(23), 9038-9046 (2009).

174 Resnick KE, Alder H, Hagan JP, Richardson DL, Croce CM, Cohn DE: The detection of differentially expressed microRNAs from the serum of ovarian cancer patients using a novel real-time PCR platform. Gynecol. Oncol. 112(1), 55-59 (2009).

175 Resnick KE, Cohn DE, Ivanov I, Liu C, Taccioli C, Croce CM: miRNA profile and advanced stage endometrial cancer. J. Clin. Oncol. 26 (May 20 Supplement) (2008) (Abstract 5561).

176 Cochrane DR, Spoelstra NS, Howe EN, Nordeen SK, Richer JK: MicroRNA-200c mitigates invasiveness and restores sensitivity to microtubule-targeting chemotherapeutic agents. Mol. Cancer Ther. 8(5), 1055-1066 (2009).
177 Boren T, Xiong Y, Hakam A et al.: MicroRNAs and their target messenger RNAs associated with endometrial carcinogenesis. Gynecol. Oncol. 110(2), 206-215 (2008).

178 Nam S, Li M, Choi K, Balch C, Kim S, Nephew KP: MicroRNA and mRNA integrated analysis (MMIA): a web tool for examining biological functions of microRNA expression. Nucleic Acids Res. 37(Web Server issue), W356-W362 (2009).

179 Kuokkanen S, Chen B, Ojalvo L, Benard L, Santoro N, Pollard JW: Genomic profiling of microRNAs and messenger RNAs reveals hormonal regulation in microRNA expression in human endometrium. Biol. Reprod. 82(4), 791-801 (2009).

180 Pan Q, Luo X, Toloubeydokhti T, Chegini N: The expression profile of micro-RNA in endometrium and endometriosis and the influence of ovarian steroids on their expression. Mol. Hum. Reprod. 13(11), 797-806 (2007).

181 Matei DE, Nephew KP: Epigenetic therapies for chemoresensitization of epithelial ovarian cancer. Gynecol. Oncol. 116(2), 195-201 (2010).

182 Takai N, Kawamata N, Walsh CS et al.: Discovery of epigenetically masked tumor suppressor genes in endometrial cancer. Mol. Cancer Res. 3(5), 261-269 (2005).

183 Nguyen CT, Weisenberger DJ, Velicescu M et al:: Histone H3-lysine 9 methylation is associated with aberrant gene silencing in cancer cells and is rapidly reversed by 5-aza-2'-deoxycytidine. Cancer Res. 62(22), 6456-6461 (2002)

184 Yoo CB, Jeong S, Egger G et al.: Delivery of 5 -aza-2'-deoxycytidine to cells using oligodeoxynucleotides. Cancer Res. 67(13), 6400-6408 (2007).

185 Balch C, Yan P, Craft T et al:: Antimitogenic and chemosensitizing effects of the methylation inhibitor zebularine in ovarian cancer. Mol. Cancer Ther. 4(10), 1505-1514 (2005).

186 Leu YW, Rahmatpanah F, Shi H et al.: Double RNA interference of DNMT3b and DNMT1 enhances DNA demethylation and gene reactivation. Cancer Res. 63(19), 6110-6115 (2003).

187 Plummer R, Vidal L, Griffin M et al.: Phase I study of MG98, an oligonucleotide antisense inhibitor of human DNA methyltransferase 1 , given as a 7-day infusion in patients with advanced solid tumors. Clin. Cancer Res. 15(9), 3177-3183 (2009).

188 Siedlecki P, Garcia Boy R, Musch T et al.: Discovery of two novel, small-molecule inhibitors of DNA methylation. J. Med. Chem. 49(2), 678-683 (2006).
189 Brueckner B, Garcia Boy R, Siedlecki P et al. Epigenetic reactivation of tumor suppressor genes by a novel small-molecule inhibitor of human DNA methyltransferases. Cancer Res. 65(14), 6305-6311 (2005).

190 Datta J, Ghoshal K, Denny WA et al: A new class of quinoline-based DNA hypomethylating agents reactivates tumor suppressor genes by blocking DNA methyltransferase 1 activity and inducing its degradation. Cancer Res. 69(10), 4277-4285 (2009).

191 Candelaria M, Gallardo-Rincon D, Arce C et al:: A Phase II study of epigenetic therapy with hydralazine and magnesium valproate to overcome chemotherapy resistance in refractory solid tumors. Ann. Oncol. 18(9), 1529-1538 (2007).

192 Minucci S, Pelicci PG: Histone deacetylase inhibitors and the promise of epigenetic (and more) treatments for cancer. Nat. Rev. Cancer 6(1), 38-51 (2006).

193 Qiu L, Burgess A, Fairlie DP, Leonard H, Parsons PG, Gabrielli BG: Histone deacetylase inhibitors trigger a G2 checkpoint in normal cells that is defective in tumor cells. Mol. Biol. Cell 11(6), 2069-2083 (2000).

194 Strait KA, Warnick CT, Ford CD, Dabbas B, Hammond EH, Ilstrup SJ: Histone deacetylase inhibitors induce G2-checkpoint arrest and apoptosis in cisplatinum-resistant ovarian cancer cells associated with overexpression of the Bcl-2-related protein Bad. Mol. Cancer Ther. 4(4), 603-611 (2005).

195 Choudhary C, Kumar C, Gnad F et al.: Lysine acetylation targets protein complexes and co-regulates major cellular functions. Science 325(5942), 834-840 (2009).

196 Batty N, Malouf GG, Issa JP: Histone deacetylase inhibitors as anti-neoplastic agents. Cancer Lett. 280(2), 192-200 (2009).

197 Plumb JA, Finn PW, Williams RJ et al.: Pharmacodynamic response and inhibition of growth of human tumor xenografts by the novel histone deacetylase inhibitor PXD101. Mol. Cancer Ther. 2(8), 721-728 (2003).

198 Qian X, LaRochelle WJ, Ara G et al.: Activity of PXD101, a histone deacetylase inhibitor, in preclinical ovarian cancer studies. Mol. Cancer Ther. 5(8), 2086-2095 (2006).

199 Uchida H, Maruyama T, Nagashima T, Asada H, Yoshimura Y: Histone deacetylase inhibitors induce differentiation of human endometrial adenocarcinoma cells through up-regulation of glycodelin. Endocrinology 146(12), 5365-5373 (2005).

200 Takai N, Desmond JC, Kumagai T et al.: Histone deacetylase inhibitors have a profound antigrowth activity in endometrial cancer cells. Clin. Cancer Res. 10(3), 1141-1149 (2004). 
201 Ahn MY, Jung JH, Na YJ, Kim HS: A natural histone deacetylase inhibitor, Psammaplin A, induces cell cycle arrest and apoptosis in human endometrial cancer cells. Gynecol. Oncol. 108(1), 27-33 (2008).

202 Ahn MY, Chung HY, Choi WS, Lee BM, Yoon S, Kim HS: Anti-tumor effect of apicidin on Ishikawa human endometrial cancer cells both in vitro and in vivo by blocking histone deacetylase 3 and 4. Int. J. Oncol. 36(1), 125-131 (2010).

203 Takai N, Ueda T, Nishida M, Nasu K, Narahara H: Anticancer activity of MS-275, a novel histone deacetylase inhibitor, against human endometrial cancer cells. Anticancer Res. 26(2A), 939-945 (2006).

204 Jiang S, Dowdy SC, Meng XW et al:: Histone deacetylase inhibitors induce apoptosis in both Type I and Type II endometrial cancer cells. Gynecol. Oncol. 105(2), 493-500 (2007).

205 Takai N, Ueda T, Nishida M, Nasu K, Narahara H: M344 is a novel synthesized histone deacetylase inhibitor that induces growth inhibition, cell cycle arrest, and apoptosis in human endometrial cancer and ovarian cancer cells. Gynecol. Oncol. 101(1), 108-113 (2006).

206 Rocha W, Sanchez R, Deschenes J et al.: Opposite effects of histone deacetylase inhibitors on glucocorticoid and estrogen signaling in human endometrial Ishikawa cells. Mol. Pharmacol. 68(6), 1852-1862 (2005).

207 Modesitt SC, Sill M, Hoffman JS, Bender DP: A Phase II study of vorinostat in the treatment of persistent or recurrent epithelial ovarian or primary peritoneal carcinoma: a Gynecologic Oncology Group study. Gynecol. Oncol. 109(2), 182-186 (2008).

208 Mackay H, Hirte HW, Covens A et al: A Phase II trial of the histone deacetylase inhibitor belinostat (PXD101) in patients with platinum resistant epithelial ovarian tumors and micropapillary/borderline (LMP) ovarian tumors. A PMH Phase II consortium trial. J. Clin. Oncol. 26(15S) (May 20 Supplement) (2008) (Abstract 5518).

209 Morey L, Brenner C, Fazi F et al.: MBD3, a component of the NuRD complex, facilitates chromatin alteration and deposition of epigenetic marks. Mol. Cell Biol. 28(19), 5912-5923 (2008).

210 Terasawa K, Sagae S, Toyota M et al.: Epigenetic inactivation of TMS1/ASC in ovarian cancer. Clin. Cancer Res. 10(6), 2000-2006 (2004).

211 Xiong Y, Dowdy SC, Gonzalez Bosquet J et al.: Epigenetic-mediated upregulation of progesterone receptor $\mathrm{B}$ gene in endometrial cancer cell lines. Gynecol. Oncol. 99(1), 135-141 (2005).
212 Shi H, Wei SH, Leu YW et al:: Triple analysis of the cancer epigenome: an integrated microarray system for assessing gene expression, DNA methylation, and histone acetylation. Cancer Res. 63(9), 2164-2171 (2003).

213 Venturelli S, Armeanu S, Pathil A et al: Epigenetic combination therapy as a tumor-selective treatment approach for hepatocellular carcinoma. Cancer 109(10), 2132-2141 (2007).

214 Cameron EE, Bachman KE, Myohanen S, Herman JG, Baylin SB: Synergy of demethylation and histone deacetylase inhibition in the re-expression of genes silenced in cancer. Nat. Genet. 21(1), 103-107 (1999).

215 Braiteh F, Soriano AO, Garcia-Manero G et al.: Phase I study of epigenetic modulation with 5-azacytidine and valproic acid in patients with advanced cancers. Clin. Cancer Res. 14(19), 6296-6301 (2008).

216 Plumb JA, Strathdee G, Sludden J, Kaye SB, Brown R: Reversal of drug resistance in human tumor xenografts by $2^{\prime}$-deoxy-5azacytidine-induced demethylation of the hMLH1 gene promoter. Cancer Res. 60 (21), 6039-6044 (2000).

217 Lin CT, Lai HC, Lee HY et al.: Valproic acid resensitizes cisplatin-resistant ovarian cancer cells. Cancer Sci. 99(6), 1218-1226 (2008).

218 Yang YT, Balch C, Kulp SK, Mand MR, Nephew KP, Chen CS: A rationally designed histone deacetylase inhibitor with distinct antitumor activity against ovarian cancer. Neoplasia 11(6), 552-563 (2009).

219 Dowdy SC, Jiang S, Zhou XC et al:: Histone deacetylase inhibitors and paclitaxel cause synergistic effects on apoptosis and microtubule stabilization in papillary serous endometrial cancer cells. Mol. Cancer Ther. 5(11), 2767-2776 (2006).

220 Appleton K, Mackay HJ, Judson I et al.: Phase I and pharmacodynamic trial of the DNA methyltransferase inhibitor decitabine and carboplatin in solid tumors. J. Clin. Oncol. 25(29), 4603-4609 (2007).

221 Glasspool RM, Gore M, Rustin G et al:: Randomized Phase II study of decitabine in combination with carboplatin compared with carboplatin alone in patients with recurrent advanced ovarian cancer. J. Clin. Oncol. 26(15S) (May 20 Supplement), (2009) (Abstract 5562).

222 Bast RC, Iyer RB, Hu W et al.: A Phase IIa study of a sequential regimen using azacitidine to reverse platinum resistance to carboplatin in patients with platinum resistant or refractory epithelial ovarian cancer. J. Clin. Oncol. 26(15S) (May 20 Supplement) (2008) (Abstract 3500).
223 Cooper AL, Greenberg VL, Lancaster PS, van Nagell JR Jr, Zimmer SG, Modesitt SC: In vitro and in vivo histone deacetylase inhibitor therapy with suberoylanilide hydroxamic acid (SAHA) and paclitaxel in ovarian cancer. Gynecol. Oncol. 104(3), 596-601 (2006).

224 Dietrich CS 3rd, Greenberg VL, DeSimone CP et al.: Suberoylanilide hydroxamic acid (SAHA) potentiates paclitaxel-induced apoptosis in ovarian cancer cell lines. Gynecol. Oncol. 116(1), 126-130 (2010).

225 Sonnemann J, Gange J, Pilz S et al: Comparative evaluation of the treatment efficacy of suberoylanilide hydroxamic acid (SAHA) and paclitaxel in ovarian cancer cell lines and primary ovarian cancer cells from patients. BMC Cancer 6, 183 (2006).

226 Steele N, Finn P, Brown R, Plumb JA: Combined inhibition of DNA methylation and histone acetylation enhances gene re-expression and drug sensitivity in vivo. Br. J. Cancer 100(5), 758-763 (2009).

227 Simpson AJ, Caballero OL, Jungbluth A, Chen YT, Old LJ: Cancer/testis antigens, gametogenesis and cancer. Nat. Rev. Cancer 5(8), 615-625 (2005).

228 Karpf AR: A potential role for epigenetic modulatory drugs in the enhancement of cancer/germ-line antigen vaccine efficacy. Epigenetics 1(3), 116-120 (2006).

229 Poleshko A, Einarson MB, Shalginskikh N et al: : Identification of a functional network of human epigenetic silencing factors. J. Biol. Chem. 285(1), 422-433 (2010).

230 Melnikov A, Scholtens D, Godwin A, Levenson V: Differential methylation profile of ovarian cancer in tissues and plasma. J. Mol. Diagn. 11(1), 60-65 (2009).

231 Huang YW, Jansen RA, Fabbri E et al:: Identification of candidate epigenetic biomarkers for ovarian cancer detection. Oncol. Rep. 22(4), 853-861 (2009).

232 Feng Q, Deftereos G, Hawes SE et al.: DNA hypermethylation, Her-2/neu overexpression and $\mathrm{p} 53$ mutations in ovarian carcinoma. Gynecol. Oncol. 111(2), 320-329 (2008).

$233 \mathrm{Wu}$ Q, Lothe RA, Ahlquist T et al: DNA methylation profiling of ovarian carcinomas and their in vitro models identifies HOXA9, HOXB5, SCGB3A1, and CRABP1 as novel targets. Mol. Cancer 6, 45 (2007).

234 Akahira J, Sugihashi Y, Suzuki T et al: Decreased expression of 14-3-3 $\sigma$ is associated with advanced disease in human epithelial ovarian cancer: its correlation with aberrant DNA methylation. Clin. Cancer Res. 10(8), 2687-2693 (2004).

235 Socha MJ, Said N, Dai Y et al.: Aberrant promoter methylation of SPARC in ovarian cancer. Neoplasia 11(2), 126-135 (2009). 
236 Staub J, Chien J, Pan Y et al.: Epigenetic silencing of HSulf-1 in ovarian cancer: implications in chemoresistance. Oncogene 26(34), 4969-4978 (2007).

237 Chaudhry P, Srinivasan R, Patel FD: Utility of gene promoter methylation in prediction of response to platinum-based chemotherapy in epithelial ovarian cancer (EOC). Cancer Invest. 27(8), 877-884 (2009).

238 Swisher EM, Gonzalez RM, Taniguchi T et al.: Methylation and protein expression of DNA repair genes: association with chemotherapy exposure and survival in sporadic ovarian and peritoneal carcinomas. Mol. Cancer 8, 48 (2009).

239 Teodoridis JM, Hall J, Marsh S et al:: CpG island methylation of DNA damage response genes in advanced ovarian cancer. Cancer Res. 65(19), 8961-8967 (2005).

240 Chou JL, Su HY, Chen LY et al.: Promoter hypermethylation of $F B X O 32$, a novel TGF- $\beta /$ SMAD 4 target gene and tumor suppressor, is associated with poor prognosis in human ovarian cancer. Lab. Invest. 90(3), 414-425 (2010).

241 Su HY, Lai HC, Lin YW, Chou YC, Liu CY, Yu MH: An epigenetic marker panel for screening and prognostic prediction of ovarian cancer. Int. J. Cancer 124(2), 387-393 (2009).

242 Chan MW, Wei SH, Wen P et al.: Hypermethylation of $18 \mathrm{~S}$ and $28 \mathrm{~S}$ ribosomal DNAs predicts progression-free survival in patients with ovarian cancer. Clin. Cancer Res. 11(20), 7376-7383 (2005).

243 Muller HM, Millinger S, Fiegl H et al.: Analysis of methylated genes in peritoneal fluids of ovarian cancer patients: a new prognostic tool. Clin. Chem. 50 (11), 2171-2173 (2004).

244 Yang N, Kaur S, Volinia S et al.: MicroRNA microarray identifies Let-7i as a novel biomarker and therapeutic target in human epithelial ovarian cancer. Cancer Res. 68(24), 10307-10314 (2008).

245 Cowden Dahl KD, Dahl R, Kruichak JN, Hudson LG: The epidermal growth factor receptor responsive miR-125a represses mesenchymal morphology in ovarian cancer cells. Neoplasia 11(11), 1208-1215 (2009).

246 Sorrentino A, Liu CG, Addario A, Peschle C, Scambia G, Ferlini C: Role of microRNAs in drug-resistant ovarian cancer cells. Gynecol. Oncol. 111(3), 478-486 (2008).

247 Zhu H, Wu H, Liu X et al.: Role of microRNA miR-27a and miR-451 in the regulation of MDR1/P-glycoprotein expression in human cancer cells. Biochem. Pharmacol. 76(5), 582-588 (2008).
248 Flavin R, Smyth P, Barrett C et al.: miR-29b expression is associated with disease-free survival in patients with ovarian serous carcinoma. Int. J. Gynecol. Cancer 19(4), 641-647 (2009).

249 Wyman SK, Parkin RK, Mitchell PS et al: Repertoire of microRNAs in epithelial ovarian cancer as determined by next generation sequencing of small RNA cDNA libraries. PLoS One 4(4), E5311 (2009).

250 Bearfoot JL, Choong DY, Gorringe KL, Campbell IG: Genetic analysis of cancerimplicated MicroRNA in ovarian cancer. Clin. Cancer Res. 14(22), 7246-7250 (2008).

251 Yang Y, Chaerkady R, Beer MA, Mendell JT, Pandey A: Identification of miR-21 targets in breast cancer cells using a quantitative proteomic approach. Proteomics 9(5), 1374-1384 (2009).

252 Boren T, Xiong Y, Hakam A et al.: MicroRNAs and their target messenger RNAs associated with ovarian cancer response to chemotherapy. Gynecol. Oncol. 113(2), 249-255 (2009).

253 Taylor DD, Gercel-Taylor C: MicroRNA signatures of tumor-derived exosomes as diagnostic biomarkers of ovarian cancer. Gynecol. Oncol. 110(1), 13-21 (2008).

254 Bendoraite A, Knouf EC, Garg KS et al.: Regulation of miR-200 family microRNAs and ZEB transcription factors in ovarian cancer: evidence supporting a mesothelial-to-epithelial transition. Gynecol. Oncol. 116(1), 117-125 (2010).

- Provides further support for epithelial differentiation in early ovarian tumorigenesis, based on miR expression.

255 Helleman J, Jansen MP, Burger C, van der Burg ME, Berns EM: Integrated genomics of chemotherapy resistant ovarian cancer: a role for extracellular matrix, TGF $\beta$ and regulating microRNAs. Int. J. Biochem. Cell Biol. 42(1), 25-30 (2010).

256 Ji J, Yamashita T, Budhu A et al:: Identification of microRNA-181 by genome-wide screening as a critical player in EpCAM-positive hepatic cancer stem cells. Hepatology 50 (2), 472-480 (2009).

257 Yu J, Ryan DG, Getsios S, OliveiraFernandes M, Fatima A, Lavker RM: MicroRNA-184 antagonizes microRNA-205 to maintain SHIP2 levels in epithelia. Proc. Natl Acad. Sci. USA 105(49), 19300-19305 (2008).

258 Fukao T, Fukuda Y, Kiga K et al.: An evolutionarily conserved mechanism for microRNA-223 expression revealed by microRNA gene profiling. Cell 129(3), 617-631 (2007).

259 Wurdinger T, Tannous BA, Saydam O et al: : miR-296 regulates growth factor receptor overexpression in angiogenic endothelial cells. Cancer Cell 14(5), 382-393 (2008).
260 Yang WT, Lewis MT, Hess K et al.: Decreased TGF $\beta$ signaling and increased COX2 expression in high risk women with increased mammographic breast density. Breast Cancer Res. Treat 119(2), 305-314 (2010).

261 Nasser MW, Datta J, Nuovo G et al.: Down-regulation of micro-RNA-1 (miR-1) in lung cancer. Suppression of tumorigenic property of lung cancer cells and their sensitization to doxorubicin-induced apoptosis by miR-1. J. Biol. Chem. 283(48), 33394-33405 (2008).

262 Guo LM, Pu Y, Han Z et al: : MicroRNA-9 inhibits ovarian cancer cell growth through regulation of NF-кB1. FEBS J. 276(19), 5537-5546 (2009).

263 Chang TC, Yu D, Lee YS et al.: Widespread microRNA repression by Myc contributes to tumorigenesis. Nat. Genet. 40(1), 43-50 (2008).

264 Hossain A, Kuo MT, Saunders GF: Mir-17-5p regulates breast cancer cell proliferation by inhibiting translation of AIB1 mRNA. Mol. Cell Biol. 26(21), 8191-8201 (2006).

265 Xu N, Papagiannakopoulos T, Pan G, Thomson JA, Kosik KS: MicroRNA-145 regulates OCT4, SOX2, and KLF4 and represses pluripotency in human embryonic stem cells. Cell 137(4), 647-658 (2009).

266 Fasanaro P, Greco S, Lorenzi M et al.: An integrated approach for experimental target identification of hypoxia-induced miR-210. J. Biol. Chem. 284(50), 35134-35143 (2009).

267 Giannakakis A, Sandaltzopoulos R, Greshock J et al.: miR-210 links hypoxia with cell cycle regulation and is deleted in human epithelial ovarian cancer. Cancer Biol. Ther. 7(2), 255-264 (2008).

268 Tavazoie SF, Alarcon C, Oskarsson T et al.: Endogenous human microRNAs that suppress breast cancer metastasis. Nature 451(7175), 147-152 (2008).

269 Abdelmohsen K, Srikantan S, Kuwano Y, Gorospe M: miR-519 reduces cell proliferation by lowering RNA-binding protein HuR levels. Proc. Natl Acad. Sci. USA 105(51), 20297-20302 (2008).

270 Fiegl H, Gattringer C, Widschwendter A et al.: Methylated DNA collected by tampons - a new tool to detect endometrial cancer. Cancer Epidemiol. Biomarkers Prev. 13(5), 882-888 (2004).

271 Mhawech-Fauceglia P, Smiraglia DJ, Bshara W et al:: Prostate-specific membrane antigen expression is a potential prognostic marker in endometrial adenocarcinoma. Cancer Epidemiol. Biomarkers Prev. 17(3), 571-577 (2008). 
272 Jo H, Kim JW, Kang GH et al.: Association of promoter hypermethylation of the RASSF1A gene with prognostic parameters in endometrial cancer. Oncol. Res. 16(4), 205-209 (2006).

273 Suehiro Y, Okada T, Anno K et al.: Aneuploidy predicts outcome in patients with endometrial carcinoma and is related to lack of $\mathrm{CDH} 13$ hypermethylation. Clin. Cancer Res. 14(11), 3354-3361 (2008).

274 Wu W, Lin Z, Zhuang Z, Liang X: Expression profile of mammalian microRNAs in endometrioid adenocarcinoma. Eur. J. Cancer Prev. 18(1), 50-55 (2009).

275 Hiroki E, Akahira JI, Suzuki F et al.: Changes in microRNA expression levels correlate with clinicopathological features and prognoses in endometrial serous adenocarcinomas. Cancer Sci. 101(1), 241-249 (2009).

276 Chung TK, Cheung TH, Huen NY et al: Dysregulated microRNAs and their predicted targets associated with endometrioid endometrial adenocarcinoma in Hong Kong women. Int. J. Cancer 124(6), 1358-1365 (2009).

277 Orom UA, Nielsen FC, Lund AH: MicroRNA-10a binds the ${ }^{\prime}$ UTR of ribosomal protein mRNAs and enhances their translation. Mol. Cell 30(4), 460-471 (2008).

278 Mayr D, Kanitz V, Anderegg B et al.: Analysis of gene amplification and prognostic markers in ovarian cancer using comparative genomic hybridization for microarrays and immunohistochemical analysis for tissue microarrays. Am. J. Clin. Pathol. 126(1), 101-109 (2006)

279 Kim YK, Yu J, Han TS et al.: Functional links between clustered microRNAs: suppression of cell-cycle inhibitors by microRNA clusters in gastric cancer. Nucleic Acids Res. 37(5), 1672-1681 (2009).

280 Dalmay T, Edwards DR: MicroRNAs and the hallmarks of cancer. Oncogene 25(46), 6170-6175 (2006).

281 Lujambio A, Calin GA, Villanueva A et al.: A microRNA DNA methylation signature for human cancer metastasis. Proc. Natl Acad. Sci. USA 105(36), 13556-13561 (2008).

282 Kawahara Y, Zinshteyn B, Sethupathy P, Iizasa H, Hatzigeorgiou AG, Nishikura K: Redirection of silencing targets by adenosineto-inosine editing of miRNAs. Science 315(5815), 1137-1140 (2007)
283 To KK, Zhan Z, Litman T, Bates SE: Regulation of $A B C G 2$ expression at the 3 untranslated region of its mRNA through modulation of transcript stability and protein translation by a putative microRNA in the $S 1$ colon cancer cell line. Mol. Cell Biol. 28(17), 5147-5161 (2008).

284 Toloubeydokhti T, Pan Q, Luo X, Bukulmez O, Chegini $\mathrm{N}$ : The expression and ovarian steroid regulation of endometrial micro-RNAs. Reprod Sci. 15(10), 993-1001 (2008).

\section{Websites}

301 American Cancer Society, GA, USA: Cancer Facts and Figures 2008 www.cancer.org/downloads/ STT/2008CAFFfinalsecured.pdf

302 A web tool for examining biological functions of microRNA expression by integration with mRNA expression http://cancer.informatics.indiana.edu/mmia

303 Herrstedt J: A Phase I/II non-comparative study of paclitaxel plus carboplatin in combination with vorinostat in patient with advanced, recurrent, epithelial ovarian cancer. ClinicalTrials.gov, MD, USA: National Library of Medicine (US) 2000-2009 www.clinicaltrials.gov/ct2/show/NCT007727 98? term $=$ NCT00772798 \& rank $=1$

304 Matulonis U: Phase IB/II study of combination vorinostat, carboplatin and gemcitabine plus vorinostat maintenance in women with recurrent, platinum-sensitive epithelial ovarian, fallopian tube, or peritoneal cancer. ClinicalTrials.gov, MD, USA: National Library of Medicine (US) 2000-2009 www.clinicaltrials.gov/ct2/show/NCT009100 00 ?term $=$ NCT00910000 \&rank $=1$

305 Matei D: Phase I/II trial of decitabine as a sensitizer to carboplatin in platinum resistant recurrent ovarian cancer. ClinicalTrials.gov, MD, USA: National Library of Medicine (US) 2000-2010 www.clinicaltrials.gov/ct2/show/ NCT00477386? term $=$ matei $\&$ rank $=1$

306 TopoTarget A/S: A Phase I/II safety, pharmacodynamic, and pharmacokinetic study of intravenously administered pxd101 plus carboplatin or paclitaxel or both in patients with advanced solid tumours. ClinicalTrials. gov, MD, USA: National Library of Medicine (US) 2000-2009 www.clinicaltrials.gov/ct2/show/NCT0042188 9? term = NCT00421889\&rank=
307 Gallardo D: Randomized, double-blind, Phase III trial of chemotherapy plus the transcriptional therapy hydralazine and magnesium valproate versus chemotherapy plus placebo in cisplatin-resistant recurrent ovarian cancer. ClinicalTrials.gov, MD, USA: National Library of Medicine (US) 2000-2009 www.clinicaltrials.gov/ct2/show/NCT00533 299? term $=$ NCT00533299\& 2 rank $=1$

308 Falchook G: Phase I/II trial of sequential azacitidine and valproic acid plus carboplatin in the treatment of patients with platinum resistant epithelial ovarian cancer. ClinicalTrials.gov, MD, USA: National Library of Medicine (US) 2000-2009 www.clinicaltrials.gov/ct2/show/NCT00529 022 ?term $=$ NCT00529022 \& $\mathrm{rank}=1$

309 Odunsi A: A Phase I clinical trial of NY-ESO-1 protein immunization in combination with 5-aza-2'-deoxycytidine (decitabine) in patients receiving liposomal doxorubicin for recurrent epithelial ovarian or primary peritoneal carcinoma. ClinicalTrials. gov, MD, USA: National Library of Medicine (US) 2000-2009

www.clinicaltrials.gov/ct2/show/NCT00887 796? term $=$ NCT00887796\&rank=1

310 Samlowski W: Inhibition of DNA methylation by 1-hr infusion of 5-aza-2'deoxycitidine (decitabine) $\times 10$ days $(\mathrm{M}-\mathrm{F})$ with escalating doses of SC pegylated (PEG) interferon- $\alpha$ 2B: a Phase I study with molecular correlates. ClinicalTrials.gov, MD, USA: National Library of Medicine (US) 2000-2009

www.clinicaltrials.gov/ct2/show/NCT00701 298? term $=$ NCT00701298 \& rank $=1$

311 Samlowski W: Inhibition of DNA methylation by 1-hr infusion of 5-aza-2'deoxycitidine (decitabine) $\times 10$ days $(\mathrm{M}-\mathrm{F})$ with escalating doses of sub-Q pegylated (PEG) interferon- $\alpha$ 2B (PEG-intron): a Phase I study with molecular correlates. ClinicalTrials.gov, MD, USA: National Library of Medicine (US) 2000-2009 www.clinicaltrials.gov/ct2/show/NCT00886 457? term $=$ NCT00886457\& $\mathrm{rank}=1$ 